\title{
Keep Calm and Be Happy: A Mixed Method Study from Character Strengths to Well-being*
}

\author{
İbrahim Demirci ${ }^{1}$ \\ Sinop University
}

\author{
Halil Ekşi ${ }^{2}$ \\ Marmara University
}

\begin{abstract}
The purpose of this study is to investigate the characteristics and sources of a peaceful and happy life. The research uses the sequential exploratory design from the mixed research designs. The grounded theory design has been used in the qualitative part of the study. In-depth interviews were performed in the qualitative section with 26 participants between the ages of 21 and 82. The structural equation model has been used in the quantitative section of the study. A total of 900 participants (548 women) between the ages of 18 and $75(\mathrm{M}=30.46, \mathrm{SD}=$ 12.94) form the sample of the study. According to the findings from the qualitative stage of the research, peaceful and happy living means having comfort and positive feelings and not having negative feelings. In spite of peace and happiness being related to each other and intertwined, peace is understood to be more permanent, prioritized, and significant compared to happiness. Sufficiency in relationships and trust, personal virtues, social virtues, acceptance, spirituality, developmental strength of problems, optimism, nature, health and economics, as well as activities and superficial solutions constitute the sources of peace and happiness. The quantitative stage of the research has found peace and happiness to positively correlate with the characteristics of tolerance, helpfulness, beliefs and spirituality, responsibility, purposefulness, worthiness, trust, and reliability. Relationships among the variables have been tested using different structural equation models. The research results are considered to contribute to the literature on positive psychology and its applications.
\end{abstract}

\section{Keywords}

Peace $\bullet$ Happiness $\bullet$ Values $\bullet$ Character strengths $\bullet$ Grounded theory $\bullet$ Structural equation model

\footnotetext{
* This manuscript was produced from the doctoral dissertation that prepared by İbrahim Demirci under the advisory of Prof. Dr. Halil Ekşi.

1 Correspondence to: İbrahim Demirci, Department of Psychological Counseling and Guidance, Sinop University, Sinop Turkey. Email: ibrahimdemircipdr@gmail.com

2 Department of Psychological Counseling and Guidance, Marmara University, İstanbul Turkey. Email: halileksi70@gmail.com

Citation: Demirci, İ., \& Ekşi, H. (2018). Keep calm and be happy: A mixed method study from character strengths to well-being. Educational Sciences: Theory \& Practice, 18, 279-330. http://dx.doi.org/10.12738/estp.2018.2.0799
} 
The concept of happiness occurs as an important concept in almost every period and society, and since the first ages has been considered as the highest good (summum bonum) by many thinkers. Various opinions have been expressed related to what happiness is and how one can be happy. Aristotle emphasized in Nichomachean Ethics (2000) that happiness (eudemonia) can be reached by revealing its potential through activities appropriate to the virtue. Marx stated that "Experience acclaims as happiest the man who has made the greatest number of people happy" (Marx \& Engels, 1835/2010, p. 8). According to Fromm (1947/2013), human development and happiness are possible only by interacting with other people as long as one lives in solidarity with them. Happiness in modern times also forms an important research topic in various disciplines such as philosophy, psychology, economics, sociology, and religious sciences. Alongside positive psychology, studies have become widespread on happiness, what it is, and how to achieve it.

The efforts of various disciplines to understand and explain the perspectives of happiness have revealed different definitions. Starting with ancient Greek philosophy until the approach of positive psychology, defining happiness has been seen through two different perspectives: hedonism and eudemonism in relation to the concept of well-being (Keyes, Shmotkin, \& Ryff, 2002; Ryan \& Deci, 2001; Waterman, 1993). While hedonism sees well-being generally as taking pleasure from life, eudemonism states well-being as the realization of human potential by viewing it as something beyond taking pleasure. The concept of eudemonism has come to mean the understanding of one's true self, or true nature, and living in accordance with it (Deci \& Ryan, 2008; Ryan \& Deci, 2001; Waterman, 1993).

Evaluating the eudemonia approach both philosophically as well as trying to explain it scientifically in terms of the hedonistic approach is quite challenging (Berridge \& Kringelbach, 2011). Conceptually, however, the viewpoints of hedonism and eudemonism overlap in happy people even though these two perspectives empirically differ. Studies performed on well-being have found well-being's hedonic and eudemonic dimensions to be related to each other (Keyes, 2002, 2005; Keyes \& Annas, 2009; Kringelbach \& Berridge, 2010). This research intends to investigate peace, an emotional reflection of eudemonia, and happiness, an emotional reflection of hedonism.

\section{Peace and Happiness}

Happiness, in accordance with the conceptualization of subjective well-being most commonly used for happiness, has been defined as a positive emotional and mental state wherein one generally experiences more positive and less negative feelings and is pleased with one's life (Diener, 1984; Diener, Suh, Lucas, \& Smith, 1999). This definition of happiness, which only focuses on emotions involving high excitation, forms a dimension of positive feelings because positive emotions are 
separated within themselves. Feelings that provide comfort, like calm, tranquility, and peace, are found aside from emotions that excite, like pleasure, joy, and happiness. Fredrickson (2001) split positive emotions in terms of activation/excitation. The emotions are found to involve low stimulation, such as satisfaction and comfort, and high stimulation, such as joy and happiness (Fredrickson, 2013). The concept of subjective well-being that evaluates happiness from the excitation perspective can be said to neglect emotionality, which involves low stimulation such as peace and quiet (Lee, Lin, Huang, \& Fredrickson, 2013). Therefore, this research has evaluated positive emotionality separately as the concepts of happiness and peace.

Studies showing that Western societies have higher levels of subjective well-being than Asian societies (Diener, Suh, Smith, \& Shao, 1995; Suh, 2002) can be explained in the way that the culture an individual belongs to affects the understanding of happiness and how it is experienced. Tsai, Knutson, and Fung (2006) found that while ideal emotions of individuals from individualistic cultures relate to emotions involving high stimulation like excitement and enthusiasm, the ideal emotions of individuals in communitarian cultures relate with emotions involving low stimulation like calmness, comfort, and peace. According to neurophysiological studies performed on emotions, the satisfaction, comfort, and trust systems, being different from the impulse and excitement systems, relate to a state of being absent from seeking and to feelings of peace, well-being, and calmness, (Gilbert, 2009, 2014).

Based on the above studies, investigating positive emotions through two different concepts -being peace and happiness- according to arousal states is thought to be able to reveal more functional results. When looked at from this perspective, while happiness relates more to hedonism and the approach of subjective well-being, peace is associated more with eudemonism and the approach of psychological well-being. While the concept of happiness shows itself through emotions like joy, pleasure, and excitement, the concept of peace comes out through emotions like comfort, calmness, and serenity.

\section{The Sources of Peace and Happiness}

Even though the hedonic and eudemonic components of well-being differ from each other, the concepts are quite related to one another. Similarly, though the concepts of peace and happiness have different meanings, they affect one another positively. Even with the variations in the factors and characteristics that reveal peace and happiness, these are seen to basically resemble each other.

One of the most common responses to asking people what makes them happy is to earn more money. However, when evaluating studies performed on this topic, the correlation is understood to be low between them in spite of happiness and money being related (Diener \& Biswas-Diener, 2002; Diener \& Lucas, 1999). US citizens 
are able to remain at the same happiness levels in spite of having doubled their income (Myers, 2000). Despite this, studies are found that show happy people earn more money and are more successful (Diener, Nickerson, Lucas, \& Sandvik, 2002; Lyubomirsky, King, \& Diener, 2005a).

In performed studies, the relationship of living conditions like income, relationship, or health status with happiness are not found to be as strong as is thought (Diener et al., 1999). The rate at which living conditions explain the variance in happiness vary from 10\% (Andrews \& Withey, 1976) to 15\% (Diener, 1984). Low-level correlations are found for happiness with the factors of income, age, education, social status, and marriage (Lyubomirsky, Sheldon, \& Schkade, 2005b). Additionally, whether or not living conditions bring about stable changes in the levels of wellbeing is completely unclear (Sheldon \& Lyubomirsky, 2006). Living conditions and individuals' personality traits, cognitions, goals, culture, and efforts to harmonize and cope play a decisive role in the effect of events on happiness (Diener et al., 1999). Some studies show happiness to be related to genetic factors (Lykken \& Tellegen, 1996; Nes, Roysamb, Tambs, Harris, \& Reichborn-Kjennerud, 2006), personality variables (Diener \& Lucas, 1999; McCrae \& Costa, 2003), and people's tendency to comply with positive life changes (Frederick \& Loewenstein, 1999; Lyubomirsky, 2011). Studies have shown that genetic factors and living conditions affect happiness at approximately $50 \%$ and $10 \%$, respectively. The remaining $40 \%$ is divided among purposeful activities. Because of the difficulty in performing a study on the topic of change in genetic factors and living conditions, intentional activities have been suggested as being able to increase happiness levels (Nelson, Kurtz, \& Lyubomirsky, 2015). Therefore focusing on the characteristics of peaceful and happy people will be useful instead of searching for peace and happiness outside of humans.

\section{Personality Characteristics and Values}

In studies on the relationship of happiness to personality traits, although happiness has been found associated with extroversion and neuroticism, the relationship between extroversion and happiness has been accepted as more important. In a study where the concept of emotional balance was used instead of neuroticism, its opposite, emotional balance was found to predict happiness more strongly than extroversion (Hills \& Argyle, 2001b). Studies show extroverts to generally be happier than introverts. The idea that extroversion is the predominant determinant of happiness is shown to not be fully compatible with the ideas philosophers have of the eudemonic viewpoint resting on people's happiness. Eudemonism can be said to suggest living a quiet life and being relatively alone to think. Introverts and extroverts have different preferences for being happy (Hills \& Argyle, 2001a, 2001b). Practices like yoga, meditation, and prayer can be said to be more related to peace rather than happiness. Peace can be seen as a reflection of emotional balance. 
Examining the relationships between well-being and character strengths will be useful if we return to the sources of peace and happiness. Character strengths strongly predict subjective and psychological well-being. In particular, emotional and interpersonal character strengths were found to be quite related to subjective well-being. The dimension of positive relations with others; the dimensions of relationship-focused character strengths, self-acceptance, and life meaning; and the dimensions of emotion-based character strengths, environmental dominance, and autonomy are more closely related to wisdom-oriented character strengths (Harzer, 2016). Studies performed in various cultures have found strong relationships between life satisfaction and the character strengths of hope, fitness, curiosity, thanksgiving, and love (Littman-Ovadia \& Lavy, 2012; Park, Peterson, \& Seligman, 2004; Shimai, Otake, Park, Peterson, \& Seligman, 2006). Character strengths are seen to positively relate to both psychological and subjective well-being.

Experimental and longitudinal studies performed on value- and character-based activities show that well-being can be increased through various purposeful activities. Purposeful activities that can increase happiness have been found such as expressing praise and gratitude (Emmons \& McCullough, 2003; Froh, Sefick, \& Emmons, 2008; Layous, Lee, Choi, \& Lyubomirsky, 2013; Lyubomirsky, Dickerhoof, Boehm, \& Sheldon, 2011; Lyubomirsky et al., 2005b; Seligman, Steen, Park, \& Peterson, 2005), expressing and applying positive thoughts and optimism (Blackwell et al., 2013; Carver, Scheier, \& Segerstrom, 2010; Lyubomirsky et al., 2011; Sheldon \& Lyubomirsky, 2006), kindness and courtesy (Buchanan \& Bardi, 2010; Dunn, Aknin, \& Norton 2008; Kerr, O’Donovan, \& Pepping, 2015; Layous, Nelson, Oberle, Schonert-Reichl, \& Lyubomirsky, 2012; Otake, Shimai, Tanaka-Matsumi, Otsui, \& Fredrickson, 2006), emphasizing and developing character strengths (Duan, Ho, Tang, Li, \& Zhang, 2014; Gander, Proyer, Ruch, \& Wyss, 2013; Nelson, Fuller, Choi, \& Lyubomirsky, 2014; Proyer, Gander, Wellenzohn, \& Ruch, 2015; Seligman et al., 2005), self-awareness practices (Mongrain, Chin, \& Shapira 2011; Neff, Kirkpatrick, \& Rude, 2007a; Zessin, Dickhäuser, \& Garbade, 2015), and meditating on love-filled feelings towards the self and others (Fredrickson, et al., 2017; Galante, Galante, Bekkers, \& Gallacher, 2014; Stell \& Farsides, 2016; Zeng, Chiu, Wang, Oei, \& Leung, 2015).

According to the intentional positive activities model, purposeful positive activities increase individual well-being, reduce depression symptoms, allow one to be healthier and more productive, and help establish good relationships with people by providing the development of positive feelings, behaviors, and thoughts and satisfying basic needs. On this point, however, the activities' characteristics, the individual's characteristics, and the individual-activity harmony are quite important (Layous, Chancellor, Lyubomirsky, Wang, \& Doraiswamy, 2011; Layous \& Lyubomirsky, 2014). Additionally, happiness enhancement studies have not been 
equally effective on individuals in different cultures (Layous \& Lyubomirsky, 2012; Layous et al., 2013). For this reason, the culture's characteristics being studied and the effects of culture on well-being must be considered when investigating the meanings of peace and happiness and their sources. Also in peace and happiness enhancement studies, cultural characteristics should also be taken into account while determining the harmony of the person and activity.

\section{Cultural Sensitivity Related to Peace and Happiness}

Even though happiness is a universal feeling, its meaning can also change according to culture. Culture affects the goals and values that are the sources of an individual's happiness. In individualistic societies like North America and Western Europe, the individual's self is in a separate situation from others. In communal cultures, the self does not separate but is in harmony with others (Diener et al., 1999; Morris, 2012; Sheldon \& Lyubomirsky, 2006). What is desired of happiness is not the same in every culture. Beliefs related to happiness in Turkey, where communal values and the Islamic belief system are widespread, can also show differences compared to Western societies. Previous studies on culture and well-being (Lee et al., 2013; Tsai et al., 2006) have shown intercultural diversity. In one study conducted to uncover basic beliefs about the nature of happiness, Africans gave importance to harmonious relations between the individual and society, while German participants emphasized individual freedom (Pflug, 2009). In African and Latin American societies apart from Europe and America, harmony and balance were seen important in similar form to Eastern societies (Joshanloo, 2014).

The state of Western and Eastern societies' perspectives of happiness and functionality are divided from one another in many ways. Cultural differences in the definitions of happiness relate to social and philosophical traditions. The effect of philosophical and religious traditions such as Hinduism, Buddhism, Taoism, Confucianism, and Sufism on this disparity is great (Joshanloo, 2014; Lu \& Gilmour, 2006). The concept of Sukha used in Buddhism comes to mean well-being that is arrived at by developing insight into the nature of reality through spiritual balance as a permanent feature instead of temporary feelings. Sukha can be reached not through conceptual or sensory stimuli but through a balanced mental state and awareness (Ekman, Davidson, Ricard, \& Wallace, 2005). According to Confucianism, Taoism, and Buddhism, the most effective path to satisfaction is to eliminate extreme desires. Satisfaction and gratitude are seen as the keys to real happiness. According to qualitative research results (Lu, 2001), one definition of happiness is to be pleased with what one has and to give thanks for everything life brings. A culture's format in defining itself carries great importance in conceptualizing happiness. In connection with these differences, while the West is self-focused, the East focuses on selftranscendence (Joshanloo, 2014; Lu \& Gilmour, 2006). 
In Islam, happiness is not a temporary emotional state. For a person to achieve lasting happiness, one must possess the proper knowledge related to self, understand the purpose of creation, and continue to live accordingly (Attas, 2011). According to Islamic belief, peace relates to doing what needs to be done knowing that God is in front of them. In this sense, being peaceful comes to mean both being in God's presence while also having the meanings of being secure, being comfortable, and not being restless (Bacanl1, 2016). The concept of balance has an important role for the Islamic conceptualization of happiness. A person's mental balance and happiness are associated with the balance between the different structures of the soul, the body and spirit, and the individual and society, as well as with a virtuous lifestyle (Joshanloo, 2013).

Kağıtçıbaşı (2014) stated that importing without question and applying Westernproduced theories to a culture in countries apart from the West lead to misapplications in applied fields such as clinical psychology. Therefore, social scientists are recommended to understand the culture they live in and produce culturally compatible theories and practices. For this reason, beginning a study using grounded theory from qualitative patterns while investigating the concepts and sources of peace and happiness is thought able to provide culturally sensitive results.

\section{The Current Research: Qualitative and Quantitative Inquiries}

The concepts of peace and happiness having differences specific to culture together with having universal characteristics is rather likely. Cross-cultural studies have stated that concepts related to well-being can show variations according to cultures. These variations have been expressed as coming from cultural structures and culture as affecting individuals' self-constructions (Kağıtçıbaşı, 2010). Evaluating the concepts of peace and happiness with cultural sensitivity and from a broad angle can help researchers arrive at more accurate results. For this reason, the research has been designed in accordance with the mixed-research model using qualitative and quantitative research methods together (Creswell, 2003, 2012; Creswell \& Plano Clark, 2011). Mixed-methods research is preferred in research because of the lack of a single source of data and the need is felt to enrich the research through a complementary second method (Creswell \& Plano Clark 2011). The study uses a sequential explorativeinvestigative mixed-research design (Creswell, 2003, 2012). Firstly, qualitative studies on the concepts of peace and happiness have been performed; later, scale development studies were done based on the findings obtained here and findings were reached by collecting the quantitative data. Lastly, the qualitative and quantitative findings have been evaluated and interpreted separately and together.

This research aims to investigate the concepts, understandings, and sources of peace and happiness. In the qualitative section of the study, understanding what participants' views are regarding a peaceful and happy life and how the concepts of 
peace and happiness are reflected in individuals' lives is intended. Additionally, how the qualities that shape individuals' lives affect their being peaceful or happy and which activities enable individuals to be peaceful or happy have been investigated. In this context, the qualitative section of the research aims to find answers to the following questions:

\section{What do peace and happiness mean?}

2.How do peace and happiness affect one's life?

3. What are the sources of peace and happiness?

Grounded theory from the qualitative research designs has been used in the first study of the research for investigating what the concepts of peace and happiness mean among people, how it is experienced, and what are their sources. The second study of the research examines the conceptual relationship of peace and happiness through values and character strengths using two different structural equation models by basing it on the conceptual handiwork revealed in the qualitative research.

\section{Study 1: The Qualitative Research Phase}

Study I uses grounded theory, a qualitative research design, to identify, give meaning to, and interpret how the participants experience phenomena related to peace and happiness, which processes are experienced while going through these, and what things affect these (Glaser \& Strauss, 1967).

\section{Method}

Participants. The study group participating in the research was identified in accordance with the theoretical sampling method. Theoretical sampling means to continue collecting data until the phase of concepts and processes that show the categories revealed in the research to have reached saturation begin to repeat (Creswell, 2012, 2013). In the interviews, information about their content and purpose were first given by performing a pre-interview with the participants. In-depth interviews were performed with 26 participants between the ages of 21 and 82 who volunteered to participate in the qualitative section of the study. The interviews lasted between 30 and 85 minutes. Of the participants, 14 are female and 12 are male; nine are between the ages of 21 and 35, eleven between 36 and 50, and six older than 60. Participants' marital statuses are seven bachelors/bachelorettes, one divorcee, 1 widow(er), and 17 spouses.

Material. Data was gathered in the research through individual face-to-face interviews and the semi-structured Peaceful and Happy Living Interview Question 
List, consisting of open-ended questions prepared and developed by the researcher as a collection tool for the purpose of obtaining individuals' views related to peace and happiness. The questions were prepared by directing them at revealing the meaning that each individual formed through their own experiences by drawing from the literature and expert opinions. Content validity of the question list was evaluated by seven experts.

\section{Procedure}

The in-depth interview technique was used in the research. In-depth interviews encourage participants to talk in depth about the topic and is said to be appropriate for collecting data in various research methods involving grounded theory (Given, 2008). In order to re-listen to the interviews performed through the peaceful and happy living interview question form and to be able to make direct quotes, voice recordings were obtained using a voice recorder by getting permission from the participants.

After the researcher listened to the audio recordings obtained from the interviews, each participant's statement was decoded and then transcribed word for word. The transcribed interviews were reread and the analysis begun. In analyzing the recorded data, the data analysis stages of grounded theory have been used. The qualitative analysis program, NVivo 8 , was used in analyzing the data.

Data analysis in grounded theory is expressed as a constant comparative analysis. Strauss and Corbin (1998) defined three types of data coding in grounded theory data analysis: open coding, axial coding, and selective coding. Data were first separated by open coding them at the level of concepts. Afterwards, concepts correlated through axial coding were brought together under categories. Lastly, the hypothesis was formed by organizing the relationships among categories around the core category using selective coding (Strauss \& Corbin, 1998).

Validity and reliability. Lincoln and Guba (1985) have recommended using the credibility of concepts in place of internal validity and the transferability of concepts in place of external validity. In the research, in-depth data was collected for providing credibility, the data analysis was checked by passing expert examination, and lastly the participants confirmed the obtained findings and concepts. To ensure transferability in the research, participants' views have been described in detail, space was given for direct quotes, and the purposeful sampling method was used in the research. Detailed information has been provided regarding how the sample was selected as well as the participants' characteristics (Lincoln \& Guba, 1985; Creswel, 2013; Creswell \& Miller, 2000).

Lincoln and Guba (1985) have recommended using consistency of concepts in place of internal reliability and confirmability of concepts in place of external reliability. The answers participants' gave to the questions included on the interview 


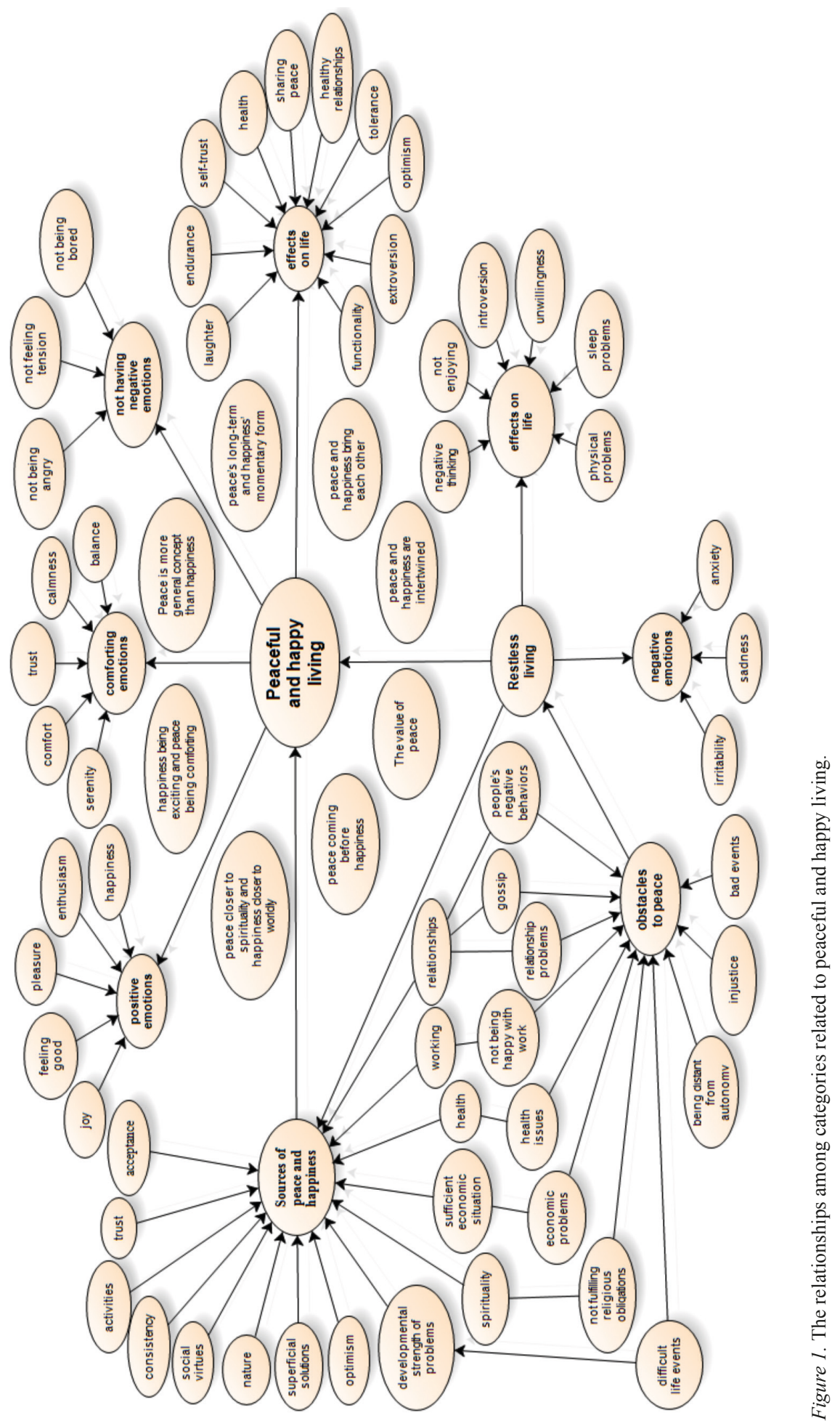


form that provided consistency in the research were recorded with a voice recorder. The revealed concepts and categories were associated by consistently encoding the obtained data. In order to ensure confirmability in the research, the raw data, and the encodings and categories revealed in the analysis results were evaluated by having them compared by a research specialist (Creswel, 2013; Creswell \& Miller, 2000; Lincoln \& Guba, 1985).

\section{Qualitative Findings and Discussion}

This section explains the findings that were revealed in the qualitative part of the research. Encodings have been presented by including direct quotations. This way, the intention is to have access to more detailed information about the participants' personal world. Information on participants' identities has been hidden; only gender and age have been included. As a result of the analyses, categories related to the concepts of peace and happiness have been formed: (a) peaceful and happy living, (2) sources of peace and happiness, (3) restless living, (4) the value of peace, (5) happiness, (6) the similarities of peace and happiness, and (7) the differences between peace and happiness. Explanations and direct quotations related to the formed categories have been included in Appendix A.

Relationships among categories following the open coding and axial coding that was performed related to the meanings, sources, results, and differences of happy and peaceful living have been disclosed in the framework of the core category of peaceful and happy living. Figure 1 shows the relationships among categories regarding peaceful and happy living. Peaceful and happy living has been expressed as experiencing positive emotions like happiness, joy, cheerful enthusiasm, and feeling good; experiencing comforting emotions like peace, relaxation, calmness, serenity, balance, and trust; and not having negative emotions like frustration, tension, or anger. While happiness relates much more to positive emotions, peace relates much more to comforting emotions. Peaceful and happy living contributes to a person's being functional, extroverted, tolerant, and optimistic; self-trust; being resistant to problems; establishing and maintaining good relationships with people; sharing peace; and smiling.

Peace and happiness are different from many angles despite being concepts quite related to each other, intertwined, and positively affecting each other. While peace relaxes the individual, happiness gives excitement. While peace is longer term, happiness is more short-term and momentary. While peace is seen closer to the spiritual dimension, happiness is seen closer to the earthly dimension. Compared to happiness, peace is a wider concept. Additionally, peace comes before happiness.

Included among the sources of peaceful and happy living are relationships, which involve qualities like family, relatives, friends, healthy human relations, and 
happy relations; acceptance, which involves qualities like acquiescence, patience, thankfulness, conviction, and being distanced from distrust; work involving qualities like success, work satisfaction, attaining goals, and diligence; consistency, which involves being one's self, self-satisfied, and doing what is needed; spirituality, which involves qualities like faith, worship, fate, and prayer; social virtues, which include the qualities of altruism, tolerance, helpfulness, and usefulness; activities such as reading, exercising, traveling, getting involved, producing, and learning new things; superficial things like thinking about different things, getting away from the surroundings, avoiding surroundings, leaving things to time, and catching bad habits; improving the direction of problems such as understanding what is important in life after experiencing problems, gaining strength to cope with issues, maturing, and strengthening family ties; trust, which includes qualities like honesty, fairness, and feeling secure; optimism; health; nature; and having a sufficient economic situation.

Handicaps to peace are seen as people's negative behaviors, dissatisfaction with work, health problems, relationship problems, economic problems, being unable to meet religious demands, difficult life events, injustice, being removed from autonomy, and bad events experienced on Earth. Restlessness contains negative emotions such as anxiety, sadness, and irritability. Negative impacts on life are found, such as negative thoughts, physical problems, sleeping problems, reluctance, being inwardly closed, and not taking pleasure.

\section{Study 2: The Quantitative Research Phase}

The quantitative section of the research investigates the relationships among values and character strengths with peace and happiness using the structural equation model. In the first section of Study II, scales for peace, happiness, tolerance, helpfulness, conviction, spirituality, personal virtues, and trust in relationships have been developed by drawing from the qualitative findings. In the second section, the concepts of peace and happiness are investigated through their relationships with the concepts of tolerance, helpfulness, conviction, and spirituality using the structural equation model. In the third section, the relationships of the concepts of peace and happiness are investigated through the concepts of responsibility, purposefulness, worthiness, trust, and reliability using the structural equation model.

\section{Method}

Sample Individuals participating in the research were identified from among undergraduate university students and adults living within the center of Turkey's Sinop Province using the multi-stage sampling method. Because two separate structural equation models have been established, two separate samples and two separate scale packets were used. 
Sample 1. The study's first sample is formed of 450 participants (281 women, 160 men, and 9 unreported). The participants' ages range from 18 to $75(M=29.71, S D$ $=12.14)$. Of the participants, $52.4 \%$ are university students $(n=236)$ and $47.6 \%$ are adults $(n=214)$.

Sample 2. The research's second sample is formed of 450 participants (267 women, 170 men, 13 unreported). The participants' ages range from 18 to 74 ( $M=$ $31.21, S D=13.65)$. Of the participants, $51.6 \%$ are university students $(n=232)$ and $48.4 \%$ are adults $(n=218)$.

Procedure. The theoretical framework related to the characteristics and sources of peaceful and happy living has been established by drawing from the findings obtained in the research's qualitative section. Afterwards, draft items were written related to the characteristics and sources of happy living using the data obtained from the interviews. The literature related to this topic was then searched and similar scales were investigated. Items were organized and updated after the studies that were performed, and the draft item pool was formed. Then the opinion was received from a teacher of Turkish for each item on the draft form. Following the Turkish teacher's views and suggestions, the items were arranged and given the scale items received their final form.

After creating the draft form, expert opinion was consulted in order to examine the consistency between the scale items and structure to be measured and to evaluate the scale items. Because scale items are being evaluated, opinions were received from eight academicians performing studies in the fields of educational sciences and psychology. The technique of Davis (1992) was used for evaluating the expert opinions. Each item was evaluated by the experts as "should stay," "needs corrections/is useful," or "should be removed/is unnecessary." Space was left alongside the items on the expert evaluation form of the scale to provide the opportunity for experts to make explanations, make corrections on an item, or to bring an item proposal. The content validity index was obtained by dividing the number of experts who stated "should stay" and "needs corrections/is useful" for an item by the total number of experts. In the evaluation result of the indexes' content validity, items with a criterion value under .80 were removed from the scale. The experts' scale items and items remaining on the scale in accordance with their views related to the scales were organized and items were added to the form as related to the suggestions. Items found in the item pool that was formed last were again evaluated together with a teacher of Turkish, and the items received their final state by making the required adjustments in terms of grammar and meaning. After finalizing the scales, they were answered by the participants. Validity and reliability analyses of the scales were performed over the obtained data.

In analyzing the validity and reliability of the scales, the following process was adhered to. In the factor analysis process, items with factor loadings less than .40 
and a difference of less than .10 among the load values in different factors were removed from the scale one by one. In the analysis process, the number of factors was decided by comparing the slope accumulation graph as well as the factors' eigenvalues and their variance ratios. Items with an item-total score correlation less than .30 and whose reliability dropped were removed from the scale. Factor analysis was again performed after this process. At last, the final version of the scale's validity and reliability analysis results are presented. Information related to the psychometric characteristics of the scales used in the study is given in Appendix B.

The Tolerance Scale, Helpfulness Scale, Conviction Scale, and Spirituality Scale are found alongside the Peace Scale and Happiness Scale in the first application packet. The first application packet examines the relationships of peace and happiness with cultural and social virtues. The Personal Virtues Scale and the Trust in Relationships Scale are found alongside the Peace Scale and Happiness Scale in the second application packet. The second packet examines the relationships of peace and happiness with personal virtues and relationships.

Data collection. Before starting the application, the researcher made explanations about the aim of the research by introducing herself and the importance of the privacy and sincerity of answers. Data from the university students was gathered in the class environment. In the adult group, the scales were placed in envelopes and distributed to the participants by making the necessary explanations; participants' answers were received in sealed envelopes. Applying the measuring tools took approximately 20-30 minutes.

Data resolutions. The state of multi-linear correlation among variables was examined for the structural equation model. Variance inflation factor $(V I F)$ having values greater than 10 and having correlation values greater than .85 between variables are indicators of multi-linear correlations (Kline, 2015). Pre-analysis VIF values and correlation values were seen to be less than 10 and .85 , respectively.

Examining whether or not variables have normal distribution happened by calculating the skewness and kurtosis values in the pre-analysis. While evaluating the case of data having normal distribution, skewness and kurtosis values between +/- 2 express sufficiency for analysis (Bachman, 2004; George \& Mallery, 2010). The variables' skewness and kurtosis values were seen to be between $+/-2$.

If the data are normally distributed in the model estimation of the structural equation model, the maximum likelihood (ML) estimation method is generally used. In situations where the data is not normally distributed, either the weighted least squares (WLS) or robust maximum likelihood (MLR) estimation methods are suggested. The data collected in the research did not meet the assumption of multiple 
normal distribution despite providing the assumption of single normal distribution. For this reason the MLR estimation method has been used. The MLR method analyzes the data through an asymptotic covariance matrix. The Satorra-Bentler $\chi^{2}$ value was used while assessing consistency in the MLR estimation method (Kline, 2015).

To determine the best of the alternative models in the structural equation model, the created models' Akaike information criterion $(A I C)$ and the expected cross-validation index (ECVI) were compared. Models having the smallest $A I C$ and $E C V I$ value are stated as providing the most consistency (Brown, 2015; Kline, 2015).

Twenty counts of data for each parameter have been stated as sufficient for the sample size in the structural equation model (Kline, 2015). In simulation studies on the sufficiency in sample size, 30 pieces of data have been proposed as sufficient for simple confirmatory factor analysis and 460 for multivariable complex structural equation models (Wolf, Harrington, Clark, \& Miller, 2013). For testing the structural equation models in this study, the sample of 450 people can be stated as sufficient.

Two separate structural equation models were established in the research. Firstly the relationship of the variables of tolerance, helpfulness, conviction, and spirituality with peace and happiness were examined in the first model. The relationship of the variables of responsibility, purposefulness, trust, and reliability with peace and happiness were examined in the second model. For identifying the relationships among variables prior to establishing the structural equation model, subjecting all variables to a cointegration factor analysis is recommended (Kline, 2015). Relationships among the variables were tested before establishing the structural equation model using a scale model.

The mediating role of the variables in the study was examined according to the suggestions of Baron and Kenny (1986). When a mediating variable is found with a dependent variable in the model, the independent variable's effect on the dependent variable dropping to a significant level is expressed as partial mediation and the independent variable's significant effect disappearing is expressed as full-mediation. The significance of the mediating variable's role has been analyzed using the Sobel (1982) test.

\section{Study 2a: Findings from the Structural Equation Model on Explaining the Rela- tionships among Cultural and Social Virtues with Peace and Happiness \\ Correlational analysis and descriptive statistics. The findings that show descriptive} statistics and the correlational coefficients among the scales and sub-dimensions have been included in Table 1. The variables skewness is seen to vary between -0.38 and -1.13 , and the kurtosis values between -0.08 and 1.94. Positive correlations were found among the variables (ranged from $r(450)=.20, p<0.01$ [spirituality and peace] to $r$ $(450)=.63, p<0.01$ [peace and happiness]), as can be seen in Table 1 . 
Table 1

Correlational Coefficients on the Relationships among the Variables of Tolerance, Helpfulness, Conviction, and Spirituality with Peace and Happiness

\begin{tabular}{lcccccc}
\hline Scales & 1 & 2 & 3 & 4 & 5 & 6 \\
\hline 1. Peace & 1 & & & & & \\
2. Happiness & $.63^{* *}$ & 1 & & & & \\
3. Tolerance & $.39^{* *}$ & $.39^{* *}$ & 1 & & & \\
4. Helpfulness & $.29^{* *}$ & $.32^{* *}$ & $.46^{* *}$ & 1 & & \\
5. Conviction & $.43^{* *}$ & $.42^{* *}$ & $.53^{* *}$ & $.54^{* *}$ & 1 & $.49^{* *}$ \\
6. Spirituality & $.20^{* *}$ & $.24^{* *}$ & $.31^{* *}$ & $.35^{* *}$ & 1 \\
\hline Mean & 29.62 & 22.88 & 23.58 & 29.78 & 25.20 & 25.14 \\
Std. Deviation & 4.88 & 3.98 & 3.58 & 3.77 & 3.94 & 4.96 \\
Skewness & -.38 & -.33 & -.42 & -.94 & -1.13 & -1.37 \\
Kurtosis & .32 & -.08 & .050 & 1.94 & 1.93 & 1.67 \\
\hline Note. $\mathrm{N}=450,{ }^{* *} p<0.01$ & & & & &
\end{tabular}

Measurement model. When examining the fit index of the measurement model, which contains all variables prior to establishing a model that explains the relationship among variables in the structural equation model, the model is seen to provide consistency at an acceptable level: $\chi_{(687, N=450)}^{2}=1094.57, p<.001 ; C F I=.98$; $N F I=.95 ; N N F I=.98 ; S R M R=.056 ; R M S E A=.036 ; 90 \%$ CI $(.032-.040)$.

Structural model. Alternative models were developed to identify the most appropriate model that best explains the relationships among variables. In Model 1 on the model where spirituality predicts peace through the partial mediation of conviction and tolerance and predicts happiness through the full-mediation of helpfulness and peace, all path coefficients were found significant except for those where spirituality predicts peace. In Model 2, all the pathways of the model where spirituality predicts peace through the full mediation of conviction and tolerance and predicts happiness through the full mediation of helpfulness and where tolerance and conviction predict happiness through the full mediation of peace have been found significant. In Model 3, all coefficients of the model where spirituality predicts conviction and happiness through the full mediation of helpfulness and predicts conviction and peace through the full mediation of tolerance and where tolerance predicts peace through the partial mediation of conviction and predicts happiness through the full mediation of peace have been found significant. In Model 4, all coefficients of the model where spirituality predicts peace, helpfulness, and tolerance through the full mediation of conviction and where conviction predicts happiness through the full mediation of peace and helpfulness, predicts tolerance through the partial mediation of helpfulness, and predicts peace through the partial mediation of tolerance have been found significant. In Model 5, all coefficients of the model where spirituality predicts peace and helpfulness though the full mediation of conviction and where tolerance and conviction predict happiness through the full mediation of peace and helpfulness have been found significant. 
While comparing the alternative models, the goodness-of-fit indexes were evaluated as acceptable, path coefficients as significant, and the $A I C$ and $E C V I$ values as low. The developed alternative models' goodness-of-fit indexes are shown in Table 2.

Table 2

Goodness-of-Fit Indexes for the Developed Alternative Structural Models

\begin{tabular}{ccccccccc}
\hline Index & $\chi^{2}$ & CFI & NFI & NNFI & SRMR & RMSEA $(90 \%$ CI $)$ & AIC & ECVI \\
\hline Model 1 & 1345.94 & .97 & .94 & .97 & .088 & $.046(.042-.049)$ & 1517.94 & 3.38 \\
Model 2 & 1349.19 & .97 & .94 & .97 & .089 & $.046(.042-.049)$ & 1521.19 & 3.39 \\
Model 3 & 1210.44 & .98 & .94 & .97 & .073 & $.041(.037-.044)$ & 1382.44 & 3.08 \\
Model 4 & 1103.67 & .98 & .95 & .98 & .057 & $.036(.032-.040)$ & 1275.67 & 2.84 \\
Model 5 & 1217.34 & .97 & .94 & .97 & .087 & $.041(.037-.045)$ & 1387.34 & 3.09 \\
\hline
\end{tabular}

Model 4, which has the lowest $A I C$ and $E C V I$ values in the comparison results, has been chosen as the model that best explains the relationship among variables. The relationship of the structural equation model to Model 4 is shown in Figure 2.

As seen in Figure 2 in the established structural equation model, the external latent variable of spirituality is seen to predict the internal latent variable of conviction $(\lambda=.59, p<.01)$; conviction to predict peace $(\beta=.28, p<.01$,), tolerance $(\beta=.46, p<.01$, ), and helpfulness $(\beta=.69, p<.01$ ); helpfulness to predict happiness $(\beta=.12, p<.05$,) and tolerance $(\beta=.35$,

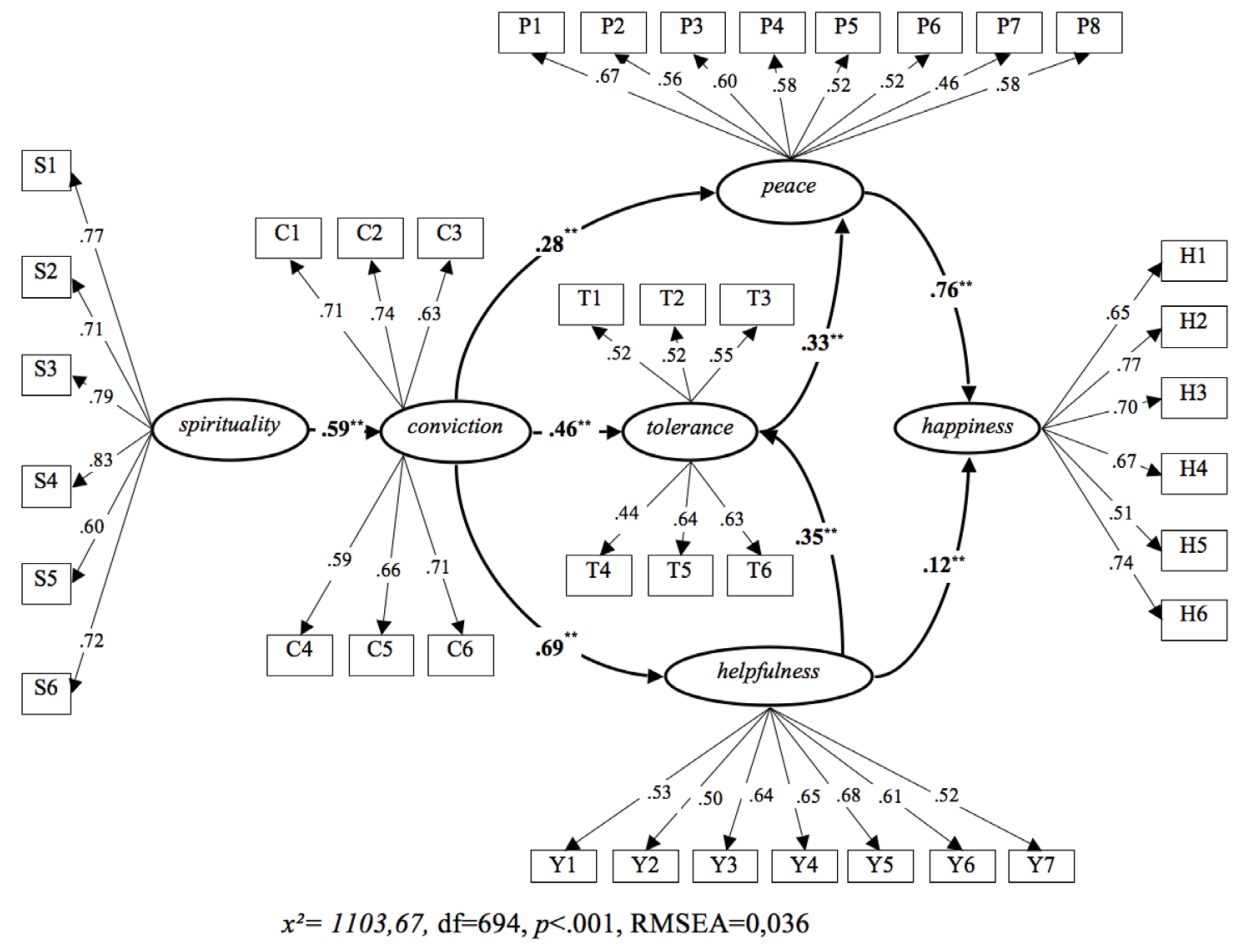

Figure 2. The relationship of the structural equation model to the variables of peace, happiness, tolerance, helpfulness, conviction, and spirituality: The Ant Model (Note: $N=450,{ }^{* *} p<0.01$ ). 
$p<.01$ ); tolerance to predict peace $(\beta=.33, p<.01$ ); and peace to predict happiness $(\beta=$ $.76, p<.01$,), directly and positively. The standardized path coefficients among the variables obtained as a result of the structural equation are shown in Table 3.

The variable of spirituality is found to indirectly predict peace $(\beta=.17, p<.01)$, tolerance $(\beta=.27, p<.01)$, and helpfulness $(\beta=.41, p<.01)$ through the mediation of conviction; the variable of conviction to indirectly predict peace $(\beta=.15, p<.01)$ through the mediation of tolerance, tolerance $(\beta=.24, p<.01)$ and happiness $(\beta=.08$, $p<.05)$ through the mediation of helpfulness, and happiness through the mediation of peace $(\beta=.21, p<.01)$; the variable of tolerance to indirectly predict happiness $(\beta=.25$, $p<.01)$ through the mediation of peace; and the variable of helpfulness to indirectly predict peace $(\beta=.12, p<.01)$ through the mediation of tolerance. The Sobel test has been used to verify the role of mediation. The mediating roles are seen significant $(p<$ $.05)$ in the results of the Sobel test concerning the relationships among variables.

Table 3

The Structural Equation Model's Standardized Path Coefficients Regarding the Variables of Peace, Happiness, Tolerance, Helpfulness, Conviction, and Spirituality

\begin{tabular}{lrlcc}
\hline Model Pathways & & & & \\
\hline Direct Link & & & Estimated & \multicolumn{1}{c}{. } \\
\hline Spirituality & $\rightarrow$ & Conviction & .59 & 9.99 \\
Conviction & $\rightarrow$ & Helpfulnes & .69 & 7.75 \\
Conviction & $\rightarrow$ & Tolerance & .46 & 5.06 \\
Conviction & $\rightarrow$ & Peace & .28 & 3.35 \\
Helpfulnes & $\rightarrow$ & Tolerance & .35 & 4.02 \\
Tolerance & $\rightarrow$ & Peace & .33 & 3.57 \\
Helpfulnes & $\rightarrow$ & Happiness & .12 & 2.08 \\
Peace & $\rightarrow$ & Happiness & .76 & 9.99 \\
Indirect Link & & & Estimated & $z$ \\
Spirituality $\rightarrow$ & Conviction $\rightarrow$ & Helpfulnes & .41 & 6.12 \\
Spirituality $\rightarrow$ & Conviction $\rightarrow$ & Tolerance & .27 & 4.51 \\
Spirituality $\rightarrow$ & Conviction $\rightarrow$ & Peace & .17 & 3.17 \\
Conviction $\rightarrow$ & Helpfulnes $\rightarrow$ & Tolerance & .24 & 3.57 \\
Conviction $\rightarrow$ & Tolerance $\rightarrow$ & Peace & .15 & 2.44 \\
Conviction $\rightarrow$ & Helpfulnes $\rightarrow$ & Happiness & .08 & 2.01 \\
Conviction $\rightarrow$ & Peace $\rightarrow$ & Happiness & .21 & 3.17 \\
Helpfulnes $\rightarrow$ & Tolerance $\rightarrow$ & Peace & .12 & 2.67 \\
Tolerance $\rightarrow$ & Peace $\rightarrow$ & Happiness & .25 & 3.73 \\
\hline & & & &
\end{tabular}




\section{Discussion}

In the structural equation model explaining the relationship of peace and happiness with cultural and social virtues, spirituality has been found to predict peace, helpfulness, and tolerance through the full-mediation of conviction; conviction to predict happiness through the full-mediation of peace and helpfulness; and conviction to predict tolerance through the partial mediation of helpfulness and to predict peace through the partial mediation of tolerance. Directly and positively, Spirituality predicts conviction; conviction predicts peace, tolerance and helpfulness; helpfulness predicts happiness and tolerance; tolerance predicts peace; and peace predicts happiness. Additionally and indirectly, spirituality has been found to predict peace, tolerance, and helpfulness through the mediation of conviction; conviction to predict peace through the mediation of tolerance, to predict tolerance and happiness through the mediation of helpfulness, and to predict happiness through the mediation of peace; tolerance to predict happiness through the mediation of peace; and helpfulness to predict peace through the mediation of tolerance.

According to this model, as spirituality increases, so also does conviction. The concept of conviction is seen to be quite important in Islamic belief and Turkish culture. Spiritual values can be said to strengthen the characteristic of conviction as a reflection of religious belief. As conviction increases, so too do peace, tolerance, and helpfulness. Conviction can be said to strengthen peace as a relationship with being thankful for the current condition and content with what there is. Not being thankful for what one has, wanting more, and being bothered by what others have can be stated as negatively affecting peace. Meanwhile, being thankful and the belief that the opportunities at hand are enough strengthen the quality of helpfulness. Additionally, being grateful and accepting and not being jealous of others can increase tolerance. Spirituality indirectly strengthens peace, tolerance, and helpfulness through conviction. As spirituality increases, so does conviction, and as conviction increases, so do peace, tolerance, and helpfulness. This situation can be interpreted in the form of the characteristic of spirituality can strengthen peace, helpfulness, and tolerance through conviction and being thankful.

According to another finding, as helpfulness increases, tolerance and happiness increase. The bond that helpful people establish through those that they assist can enable them to be aware of the situation people who need help are in, becoming more understanding of them and more tolerant. On the other hand, being aware of the problems people experience can lead to unhappiness. However, being useful to someone, working to be the cure to their trouble, and helping all make a person happy. Conviction increases tolerance and happiness through the mediation of helpfulness. When conviction increases helpfulness, the increase in helpfulness also increases tolerance and happiness. Contented people can be happy when being helpful. 
According to another finding related to social virtues, being tolerant increases peace. Being understanding of others and not being bothered by differences strengthens peace. Helpfulness indirectly increase peace through the mediation of tolerance. When helpful people are more tolerant, being tolerant contributes to their being more peaceful. A person's being at peace with the self and conscientiously comfortable, feeling peaceful and secure, and being in harmony and balance strengthens that person's happiness. Conviction and tolerance indirectly increase happiness through the mediation of peace. When conviction and tolerance increase peace, peace also strengthens happiness. Peace is seen to be the strongest predictor of happiness.

This model attempts to explain peace and happiness through the values of spirituality, conviction, tolerance, and helpfulness. This model has been called the Ant Model because of the values attributed to the ant in Turkish and Islamic culture. The expression "The moderation of ants" [Karınca kararınca in Turkish] means to help as much as one can, even if only a little, and the expression "The patience of ants" [Karınca sabr1] expresses being very patient. Because the focal point of the model is conviction, this reference is considered appropriate. Additionally, ants have a social structure that exemplifies living together and cooperation.

\section{Study 2b. Findings from the Structural Equation Model Directed at Explaining the Relationships of Responsibility, Purposefulness, Worthiness, Trust, and Re- liability with Peace and Happiness}

Correlation analysis and descriptive statistics. Findings that show the correlation coefficients among the scales and sub-dimensions and the descriptive statistics have been included in Table 4. The variables' skewness values are seen to vary between -0.25 and -1.06 , and their kurtosis values from -0.09 to 1.29 . Positive correlations were found among the variables (ranged from $r(450)=.25, p<0.01$ [responsibility and trust] to $r(450)=.65, p<0.01$ [peace and happiness]), as can be seen in Table 4 .

Table 4

Correlation Coefficients Regarding the Relationships among Peace, Happiness, Responsibility, Purposefulness, Worthiness, Trust, and Reliability

\begin{tabular}{|c|c|c|c|c|c|c|c|}
\hline Scales & 1 & 2 & 3 & 4 & 5 & 6 & 7 \\
\hline 1. Peace & 1 & & & & & & \\
\hline 2. Happiness & $.65^{* *}$ & 1 & & & & & \\
\hline 3. Responsibility & $.44^{* *}$ & $.31^{* *}$ & 1 & & & & \\
\hline 4. Purposefulnes & $.50^{* *}$ & $.50^{* *}$ & $.52^{* *}$ & 1 & & & \\
\hline 5. Worthines & $.59^{* *}$ & $.52^{* *}$ & $.37^{* * *}$ & $.53^{* *}$ & 1 & & \\
\hline 6. Trust & $.47^{* *}$ & $.54^{* * *}$ & $.25^{* *}$ & $.36^{* * *}$ & $.49^{* *}$ & 1 & \\
\hline 7. Reliability & $.38^{* *}$ & $.38^{* *}$ & $.45^{* * *}$ & $.34^{* * *}$ & $.35^{* *}$ & $.45^{* *}$ & 1 \\
\hline Mean & 29.87 & 23.06 & 20.79 & 18.43 & 18.61 & 20.92 & 22.31 \\
\hline Std. Deviation & 4.94 & 4.03 & 3.15 & 3.27 & 3.44 & 3.58 & 2.61 \\
\hline Skewness & -.38 & -.35 & -.55 & -.25 & -.42 & -.81 & -1.06 \\
\hline Kurtosis & -.38 & -.30 & -.30 & -.09 & .17 & .46 & 1.29 \\
\hline
\end{tabular}

Note. $\mathrm{N}=450,{ }^{* *} p<0.01$ 
Measuring model. Before establishing the model explaining the relationships among the variables in the structural equation model, the model was seen to provide agreement at an acceptable level when examining the fit indexes of the measuring model containing all the variables: $\chi_{(681, N=450)}=1106.80, p<.001 ; C F I=.98 ; N F I=$ $.95 ;$ NNFI $=.98 ;$ SRMR $=.052 ;$ RMSEA $=.03790 \%$ CI $(.033-.041)$.

Structural model. The relationships among seven latent variables (peace, happiness, responsibility, purposefulness, worthiness, trust, and reliability) have been examined by evaluating the relationship among the scales and considering the theoretical background. Alternative models have been developed to determine which model best explains the relationships among variables and is best suited to the data.

In Model 1, all path coefficients were found to be significant in the model where responsibility, purposefulness, worthiness, trust, and reliability predict happiness through the full-mediation of peace, apart from the path coefficients where purposefulness and reliability predict peace. In Model 2, all path coefficients have been found significant in the model where trust and reliability predict peace through the full-mediation of responsibility, purposefulness, and worthiness, apart from the path coefficients where trust predicts responsibility. In Model 3 all path coefficients have been found significant in the model where responsibility, purposefulness, and worthiness predict peace through the full-mediation of trust and reliability and where trust and reliability predict happiness through the full-mediation of peace, except for those where responsibility predicts trust and where purposefulness predicts trust and reliability. In Model 4, all path coefficients in the model where responsibility, purposefulness, and worthiness predict happiness through the mediation of peace and where trust predicts happiness through the partial mediation of peace have been found significant. In Model 5, all path coefficients were found significant where responsibility, purposefulness, and worthiness predict happiness through the full-mediation of peace, where responsibility predicts trust through the full-mediation of reliability, and where trust predicts happiness through the partial mediation of peace. In Model 6, the model's path coefficients were found significant where responsibility predicts worthiness and peace through the full mediation of purposefulness and predicts trust through the full mediation of reliability, where purposefulness predicts peace through the partial mediation of worthiness and predicts happiness through the partial mediation of peace, and where trust predicts peace through the partial mediation of worthiness and predicts happiness through the partial mediation of peace. In Model 7, all path coefficients of the model where responsibility predicts peace through the full mediation of purposefulness and predicts trust through the full mediation of reliability, where trust predicts purposefulness through the full mediation of worthiness and predicts happiness through the partial mediation of peace, and where worthiness predicts peace through the partial mediation of purposefulness and predicts happiness through the full mediation of peace have been found significant. 
While comparing the tested alternative models, acceptability of the goodness-offit indexes, significance of the path coefficients, and the lowness of the AIC and $E C V I$ values were evaluated. The alternative goodness-of-fit indexes that had been developed are shown in Table 5.

Table 5

Goodness-of-Fit Indexes Related to the Developed Alternative Structural Models

\begin{tabular}{ccccccccc}
\hline Index & $\chi^{2}$ & CFI & NFI & NNFI & SRMR & RMSEA $(90 \%$ CI $)$ & AIC & ECVI \\
\hline Model 1 & 1153.67 & .98 & .96 & .98 & .054 & $.039(.035-.043)$ & 1341.67 & 2.99 \\
Model 2 & 1308.62 & .98 & .95 & .97 & .070 & $.045(.041-.048)$ & 1486.62 & 3.31 \\
Model 3 & 1331.81 & .98 & .95 & .97 & .076 & $.045(.042-.049)$ & 1511.08 & 3.37 \\
Model 4 & 1207.16 & .98 & .95 & .98 & .076 & $.041(.037-.045)$ & 1486.62 & 3.08 \\
Model 5 & 1475.16 & .98 & .95 & .98 & .082 & $.041(.038-.045)$ & 1399.65 & 3.47 \\
Model 6 & 1155.49 & .98 & .95 & .98 & .061 & $.039(.035-.042)$ & 1331.49 & 2.97 \\
Model 7 & 1161.81 & .98 & .95 & .98 & .062 & $.039(.035-.043)$ & 1337.81 & 2.98 \\
\hline
\end{tabular}

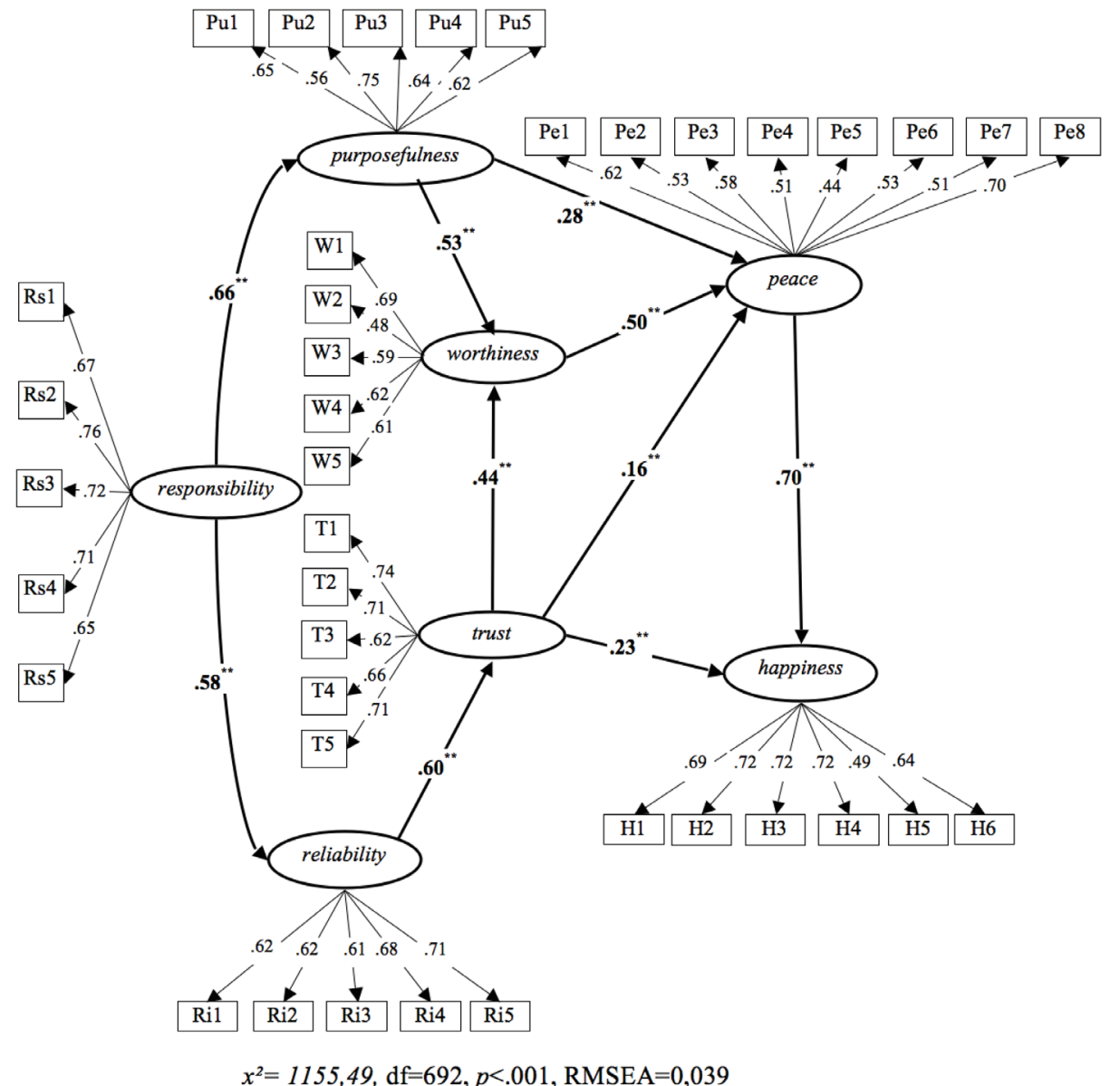

Figure 3. The structural equation model related to the variables of peace, happiness, responsibility, purposefulness, worthiness, trust, and reliability: The Bee Model (Note: $\mathrm{N}=450, * * p<0.01$ ). 
As a result of the comparisons, Model 6, having the lowest $A I C$ and $E C V I$ values, has been chosen as the model best explaining the relationship among the variables. The structural equation model shown in Figure 3 is the one related to Model 6.

In the established structural equation model as shown in Figure 3, the external latent variable of responsibility is seen to predict the internal latent variables of reliability $(\lambda$ $=.58, p<.01)$ and purposefulness $(\lambda=.66, p<.01)$; the variable of purposefulness: worthiness $(\beta=.53, p<.01)$ and peace $(\beta=.28, p<.01)$; the variable of reliability: trust $(\beta=.60, p<.01)$; the variable of trust: peace $(\beta=.16, p<.01)$, happiness $(\beta=.23, p<$ $.01)$, and worthiness $(\beta=.44, p<.01)$; the variable of worthiness: peace $(\beta=.50, p<.01)$; and the variable of peace: happiness $(\beta=.70, p<.01)$, all directly in a positive direction.

Table 6

Standardized Path Coefficients of the Structural Equation Model Related to the Variables of Peace, Happiness, Responsibility, Purposefulness, Worthiness, Trust, and Reliability

\begin{tabular}{|c|c|c|c|c|}
\hline \multicolumn{5}{|l|}{ Model pathways } \\
\hline Direct Link & & & Estimated & $t$ \\
\hline Responsibility & $\rightarrow$ & Purposefulness & .66 & 10.44 \\
\hline Responsibility & $\rightarrow$ & Reliability & .58 & 9.44 \\
\hline Reliability & $\rightarrow$ & Trust & .60 & 9.44 \\
\hline Purposefulness & $\rightarrow$ & Peace & .28 & 3.67 \\
\hline Purposefulness & $\rightarrow$ & Worthiness & .53 & 8.13 \\
\hline Worthiness & $\rightarrow$ & Peace & .50 & 4.68 \\
\hline Trust & $\rightarrow$ & Happiness & .23 & 4.58 \\
\hline Trust & $\rightarrow$ & Peace & .16 & 2.31 \\
\hline Trust & $\rightarrow$ & Worthiness & .44 & 7.34 \\
\hline Peace & $\rightarrow$ & Happiness & .70 & 9.32 \\
\hline Indirect Link & & & Estimated & $z$ \\
\hline Responsibility $\rightarrow$ & Reliability $\rightarrow$ & Trust & .35 & 6.67 \\
\hline Responsibility $\rightarrow$ & Purposefulness $\rightarrow$ & Worthiness & .35 & 6.41 \\
\hline Responsibility $\rightarrow$ & Purposefulness $\rightarrow$ & Peace & .19 & 3.46 \\
\hline Reliability $\rightarrow$ & Trust $\rightarrow$ & Peace & .10 & 2.24 \\
\hline Reliability $\rightarrow$ & Trust $\rightarrow$ & Happiness & .14 & 4.12 \\
\hline Reliability $\rightarrow$ & Trust $\rightarrow$ & Worthiness & .26 & 5.79 \\
\hline Purposefulness $\rightarrow$ & Worthiness $\rightarrow$ & Peace & .27 & 4.06 \\
\hline Purposefulness $\rightarrow$ & Peace $\rightarrow$ & Happiness & .20 & 3.41 \\
\hline Worthiness $\rightarrow$ & Peace $\rightarrow$ & Happiness & .35 & 4.18 \\
\hline Trust $\rightarrow$ & Worthiness $\rightarrow$ & Peace & .22 & 3.95 \\
\hline Trust $\rightarrow$ & Peace $\rightarrow$ & Happiness & .11 & 2.24 \\
\hline
\end{tabular}


The variable of responsibility has been found to predict trust $(\beta=.35, p<.01)$ through the mediation of reliability and to predict worthiness $(\beta=.35, p<.01)$ and peace $(\beta=.19, p<.01)$ through the mediation of purposefulness; the variable of reliability: peace $(\beta=.10, p<.01)$, happiness $(\beta=.14, p<.01)$, and worthiness $(\beta=$ $.26, p<.01)$ through the mediation of trust; the variable of purposefulness: happiness $(\beta=.20, p<.01)$ through the mediation of peace, and peace $(\beta=.27, p<.01)$ through the mediation of worthiness; the variable of worthiness: happiness $(\beta=.35, p<.01)$ through the mediation of peace; and the variable of trust: happiness $(\beta=.11, p<.01)$ through the mediation of peace, and peace $(\beta=.22, p<.01)$ through the mediation of worthiness, all indirectly. The Sobel test has been used for verifying the mediating role. In the Sobel test results regarding the relationships among variables, the mediating roles are seen to be significant $(p<.05)$. The standardized path coefficients arrived at in the structural equation results appear in Table 6.

\section{Discussion}

In the structural equation model explaining the relationships among peace and happiness through personal virtues and relations, responsibility is seen to predict worthiness and peace through the full mediation of purposefulness and to predict trust through the full mediation of reliability; purposefulness to predict peace through the partial mediation of worthiness and to predict happiness through the partial mediation of peace; and trust to predict peace through the partial mediation of worthiness and to predict happiness through the partial mediation of peace. Responsibility directly and positively predicts reliability and purposefulness, as does reliability predict trust; trust predict peace, happiness, and worthiness; worthiness predict peace; and peace predict happiness. Additionally, responsibility has been found to predict trust through the mediation of reliability and worthiness and to predict peace through the mediation of purposefulness; reliability, to predict peace, happiness, and worthiness through the mediation of trust; purposefulness, to predict happiness through the mediation of peace and peace through the mediation of worthiness; worthiness, to predict happiness through the mediation of peace; and trust, to predict happiness through the mediation of peace and peace through the mediation of worthiness, all indirectly.

According to these results, when responsibility increases purposefulness, purposefulness also strengthens worthiness and peace. Responsibility indirectly increases peace and worthiness through the mediation of purposefulness. Being responsible can be said to positively affect working toward a goal and being hopeful. People who fulfill their responsibilities and complete their work can have beliefs that gravitate towards a goal. Being directed toward a purpose and being hopeful also strengthen worthiness. Purposefulness can contribute to one feeling one's worth and being understanding towards one's self. Additionally, organizing one's life towards 
goals strengthens peace. This situation can be interpreted as feeling peaceful and worthy when people who have responsibility work towards a goal, appropriately organize their life towards goals, and are hopeful.

According to another finding on personal virtues, purposefulness both indirectly increases peace through the mediation of worthiness and happiness through the mediation of peace. Feeling one's self-worth and being understanding of one's self increase peace. People who strive to live according to their purposes can be peaceful when being understanding towards one's self. When purposefulness increases worthiness, worthiness also increases peace. When purposefulness increases peace, peace also strengthens happiness. Purposeful people can be happy when they are peaceful. When worthiness increases peace, peace also strengthens happiness. People who are understanding towards the self and feel one's self-worth can be happy because they are peaceful.

According to the results on relationships and trust, when responsibility increases reliability, reliability can also increase trust. Responsibility indirectly predicts trust through the mediation of reliability. Fulfilling responsibilities in daily life and not leaving jobs half-way can contribute to being more reliable. Reliable people can also feel trust by establishing better relationships with other people. When responsibility increases reliability, reliability also increases trust. When reliability increases trust, trust also increases peace, happiness, and worthiness. Reliability indirectly predicts peace, happiness, and worthiness through the mediation of trust. People who are reliable around others and who have social support can strengthen the qualities of being self-compassion and feeling self-worth. Additionally, trust contributes to a person feeling more peaceful and happy. When being reliable contributes to feeling trust socially, it can strengthen being peaceful, happy, and worthy. When trust increases worthiness, worthiness also strengthens peace. Feeling secure socially contributes to feeling worthy, and feeling worthy also contributes to peace. When trust increases peace, peace also strengthens happiness. Having people around that one cares about and having social support contribute to feeling peaceful and happy.

This model attempts to explain peace and happiness through the variables of responsibility, purposefulness, worthiness, trust in relationships, and reliability. This model has been called the Bee Model because of the values attributed to the bee in Turkish and Islamic culture. The saying "Busy as a bee" [Arı gibi çalışkan in Turkish] means to be very hardworking. Additionally, bees have strong illustrative associations on the topics of cooperation and division of labor. Because the model's starting points are responsibility, purposefulness, and reliability, this reference has been deemed appropriate. 


\section{General Discussion}

This study has investigated the sources and understandings of the concepts of peace and happiness through the sequential exploratory mixed-research design, first using qualitative research, then using quantitative research. Scientific studies have recently begun to address inner harmony and emotions containing low stimulation as related to happiness. The further growth of studies performed on the concept of peace in the coming years can be expressed. The Types of Positive Affect Scale (Gilbert et al., 2008); Subjective Authentic-Durable Happiness Scale (Dambrun et al., 2012); the Peace of Mind Scale (Lee et al, 2013), aimed at measuring this construct for East Asia; and The Harmony in Life Scale (Kjell, Daukantaite, Hefferon, \& Sikström, 2016), performed among both Western and Asian participants as validity studies, can be shown as examples of studies in the literature. If also assuming the qualities related to happiness are universal, the positive psychology literature emphasizes there can be differentiations in the definitions of happiness and the meanings it instills from person to person and from culture to culture. In accordance with these differentiations, the meanings and sources of happiness show variability. For this reason, scale-development studies have been performed based on the concepts previously investigated using qualitative grounded-theory research.

In this research, peace being more important and prioritized compared to happiness can be explained by generally reflecting on the collectivist-culture qualities of Turkey and the effects of Islamic belief. In research performed on the concept of peace, the negative relationship of peace with depression and anxiety has been found to be stronger compared with concepts like life satisfaction and happiness (Lee et al., 2013). Emotional balance has been found as the most powerful personal variable to predict happiness (Hills \& Argyle, 2001b). The strong relationship that the concept of peace has with variables of both positive and negative mental/spiritual health shows studies related to this concept to be needed. Investigating the meaning of happiness among the public alongside its meaning in scientific studies is quite important. The hedonic and eudemonic components of happiness have been investigated through 666 participants from seven different countries using mixed methods that combine qualitative and quantitative analyses. The results first show the psychological balance and harmony of the condition of happiness. Among different habitats, familial and social relationships have been found to relate predominantly with happiness and meaning (Delle Fave, Brdar, Freire, Vella-Brodrick, \& Wissing, 2011a).

Peace is not just seen in Eastern societies; it also stands out among the public in South America. In an anthropological study the themes of serenity and joy emerged in the definitions of happiness from the Amazon Urarina people. About 4,000 hunters and farmers of the Urarina living on the edge of the Chambira River in the Amazon forests show similarities with the rest of the world's views on good living (Walker, 2015). In 
psychological research, while social relations are accepted as a basic component of happiness, inner harmony can be said to be largely neglected. Studies performed on the topic of well-being have shown that inner harmony can be used as the conceptual background of human functionality beyond cultural characteristics (Delle Fave et al., 2016). As is seen, defining happiness through the concept of peace is not just observed in Eastern societies; it has been observed in many countries with various cultural characteristics. This study attempts to evaluate the concepts of peace and happiness together.

Studies where happiness has been scored instantly and measured at specific intervals showed that happiness changes and fluctuates throughout the day and on various days during the week (Dambrun et al., 2012; Kahneman \& Riis, 2005). Authentic and lasting happiness is related to altruistic psychological functioning characterized through charitable emotions like mercy and empathy. These feelings develop feelings of emotional balance and harmony like inner peace and serenity. Authentic and lasting happiness being relatable through the values of universality and helpfulness has been expressed in relation to Schwartz's (2012) transcending the self (Dambrun et al., 2012). The paths of happiness that include social loyalty can be said to more positively affect well-being. I-focused and other-focused understandings of happiness affect well-being differently (Ford et al., 2015). Intercultural studies have revealed theoretical differences for internal values arising from personal development, interests, and the feeling of community with external values like money, image, and popularity. Internal values, by fulfilling well the psychological needs, increase well-being and reduce stress. External values being in the fore are related to low well-being and increased stress (Kasser, 2015).

Various value-orientations can be said for the different definitions of happiness. Value orientations determine what will make oneself pleased and happy (Joshanloo et al., 2016; Oishi, Diener, Suh, \& Lucas, 1999; Schwartz, 1992, 2012). Therefore identifying personal values and character strengths in future studies and designing them appropriately for personal characteristics will be useful for increasing peace and happiness. Living in harmony with one's values and character strengths can be expressed as something that will contribute to a person's peaceful and happy living.

According to Rokeach (1973), inner peace and happiness are related to basic existential goals. Instrumental values that can be used for arriving at these purposes contain the values of honesty, being responsible, and helpfulness. This study has arrived at the conclusion that the concepts of peace and happiness positively affect each other as important goals each and that personal and social virtues contribute to reaching peace and happiness.

Below includes a discussion on the research results that have been reached as a result of combining the findings obtained from the grounded-theory research model 
used in the qualitative section and from the structural equation models used in the quantitative section of the research.

\section{Peaceful and Happy Living}

The first goal of the research has been to understand how the concepts of peace and happiness are experienced and what they have come to mean. Peace is definable as one feeling comfortable, being calm, feeling secure, not having disturbing thoughts in mind, and maintaining balance and harmony in life despite its problems. Happiness shows itself in a person's experience of positive emotions like enthusiasm, joy, and pleasure. Not being at peace has been stated in the form of experiencing negative feelings like anxiety, anger, and sadness. In peaceful and happy living, negative feelings and thoughts like tension. Anger, stress, and sadness are experienced less. Peace and happiness positively affect one another according to the category of peace and happiness' similarities that emerged in the qualitative section of the research. Peace and happiness have been expressed as nested past experiences. Findings from the quantitative section of the research support this judgment. Peace and happiness are found to positively relate. Additionally, peace has been seen as the strongest predictor of happiness.

Happiness in accordance with the hedonic point of view can be defined as experiencing more positive affections that express high excitement than negative ones (Diener, 1984; Diener et al, 1999). The dimensions of positive emotions and of not having negative emotions reached in the qualitative findings of this research appear related to the approach of subjective well-being. Emotions like happiness, joy, delight, pleasure and liveliness are acceptable indicators of an individual feeling subjectively well. However, these emotions, which include high excitement, only reflect a section of well-being. The dimension of comforting emotions that the research arrived at can be said to define well-being's lack in relation to peace. Studies performed in relation to feelings (Fredrickson, 2001; Lee et al., 2013) and emotionregulation systems (Depue \& Morrone-Strupinsky, 2005; Gilbert et al., 2008, 2012) have shown the importance of peace in the concept of well-being. The dimension of comforting feelings arrived at in the research appear related to the emotions involving low excitement and to psychological well-being. Emotions such as peace, serenity, calmness, trust, and balance form an important dimension of well-being.

This study has evaluated the concepts of peace and happiness together, and peace has emerged as more important than happiness according to the results of the qualitative research. While dealing with peace and happiness, however, the statements that people revealed have been noted according to their own emotional and cognitive evaluation. When looking at other theories on well-being, multi-dimensional approaches are understood to see more acceptance, like positive emotions, good relationships, flow, meaning, and success (Butler \& Kern, 2016; Seligman, 2011) 
or like self-acceptance, positive relations with others, autonomy, control of one's surroundings, purpose of living, and personal development (Ryff \& Singer, 2008). According to this research's conceptualization, these dimensions are related to wellbeing, but only form its sources. Well-being can be defined through the concepts of peace and happiness. The variables forming multidimensional structures expressed in previous studies can be considered as the sources of peace and happiness.

In spite of peace and happiness being interrelated concepts, they have directions that are basically different from each other. According to the qualitative research findings, peace is a more general and high level concept than happiness. Peace comes before happiness and is accepted as more important by many people. While peace is long term, happiness is more short term and momentary. While peace is closer to spirituality, happiness is closer to the earthly dimension. While peace relaxes, happiness excites. Peace forms low-stimulus emotional clusters and happiness forms high-excitement emotional clusters. Bacanlı's (2016) conceptualization of peace similarly emphasizes it to be a more important and enduring emotional state than happiness in Turkish and Islamic culture.

While cultures of the West give value to positive situations involving high stimulation, such as excitement, Eastern cultures give value to situations involving calmness and low stimulation (Tsai, 2007). As an individual's own cultural characteristics influence their ideal emotions, the increase of well-being has been presented for individuals who experience harmonious affection with their culture (Lee et al., 2013). The finding arrived at in the results of this research of peace being more important and more prioritized than happiness is seen as compatible with intercultural psychological studies.

\section{Peace and Happiness's Effect on Life}

The second aim of the research investigates how peace and happiness affect a person's living. Peaceful and happy living enables one to trust oneself, assess events from more positive angles, lead a more functional life, be more resistant to the problems experienced, smile, be more extroverted, live a healthier life, be more tolerant, and establish better relationships with people. According to the category of restless living, not being at peace causes physical problems, sleep problems, lack of desire, lack of enjoyment, withdrawal, and negative thoughts. Findings from the quantitative section of the study support this judgment. Peace and happiness have been found to positively relate to characteristics such as responsibility, purposefulness, worthiness, reliability, social trust, tolerance, helpfulness, conviction, and spirituality.

The meta-analysis that evaluated the relationship of happiness to life success shows happy people to concretely benefit in many different areas of life. The positive point 
of view happy people have towards themselves and others is seen to be successful in the areas of socialness and activities, positive social behavior, popularity, healthy behaviors, strong immune system, handling stress well, effective conflict-resolution competence, altruism, and satisfactory living. Additionally, studies have shown happy people to tend to not be self-centered or selfish and to be more collaborative, pro-community philanthropist, and other-centered (Lyubomirsky et al., 2005a).

Fredrickson's (2001) broaden-and-build theory of positive emotions revealed positive emotions to produces many sources for an individual to be able to better maintain one's living. Positive emotions are seen to increase problem-solving and stress-coping skills, productivity, and work efficiency. In addition to this, positive emotions are emphasized to bring physical and mental health to a better state and to improve psychological well-being and happiness levels (Fredrickson, 2013).

\section{The Sources of Peace and Happiness}

The third aim of the research has been to reveal the sources of peace and happiness. The sources of peace and happiness have been restructured by drawing forth from the findings reached in the qualitative and quantitative stages of the research. According to this, the sources of peace and happiness are structured as follows in the presented categories: Relationships and trust, personal virtues, social virtues, acceptance, spirituality, the developmental power of problems, optimism, nature, health, economic situation, events, and superficial solutions.

Relationships and trust. Relationships with family and friends as determinants of well-being have been widely documented for every age in in every culture (Diener $\&$ Biswas-Diener, 2008). Theoretical and empirical studies have revealed the number and quality of close relationships to have a strong and consistent relationship with happiness. Social support, secure ties, and the quality of relationships predict happiness (Demir, Orthel-Clark, Özdemir, \& Özdemir, 2015; Lakey, 2013). In studies desiring to have participants define their own happiness, happiness has been seen defined contextually as familial and social relationships (Delle Fave et al., 2016). In another study researching the relationships among happiness and the importance it is given in areas of life, family and social relationships have been found to be clearly associated with happiness among the various areas of life (Delle Fave et al., 2011a).

Personal virtues. According to various research results, the concept of self-sompassion, which relates to the concept of worthiness, has been shown related to happiness (Neff, Rude, \& Kirkpatrick, 2007b; Smeets, Neff, Alberts, \& Peters, 2014). When analyzing performed studies, strong relationships are seen to exist between self-sompassion and well-being (Neff et al., 2007a; Zessin et al., 2015). Self-sompassion has been expressed as an important source of eudemonic happiness (Neff \& Costigan, 2014). 
The personal characteristic of responsibility shows positive relationships with happiness, life satisfaction, subjective well-being and psychological well-being (Chamorro-Premuzic, Bennett, \& Furnham, 2007; Furnham \& Cheng, 1997; Hayes \& Joseph, 2003; Schmutte \& Ryff, 1997). Additionally, studies are found showing people with high levels of subjective and psychological well-being to possess responsibility (Keyes, 2002). Related to responsibility, people who seek meaning and purpose in life, go with the flow, and are not overly interested in pleasure have been stated to have higher levels of stability (Von Culin, Tsukayama, \& Duckworth, 2014).

The concept of hope, being related to purposefulness, expresses the belief that one can find and use the paths to reach their goals (Snyder, 2002). Studies performed on hope have shown hope and well-being to contain a positive relationship (Bailey \& Snyder, 2007; Stassen \& Staats, 1988). Optimism, a concept related to hope, positively affects psychological and physical health, social relations, and problem-coping (Carver \& Scheier, 2014). Additionally, hope has been seen as a mediating variable between life purpose and life satisfaction (Cotton Bronk, Hill, Lapsley, Talib, \& Finch, 2009).

Social virtues. Tolerant people have been emphasized as tending to forgive more easily, being more focused on the good aspects of their surroundings, having high awareness levels, and accepting others without judgment ( $\mathrm{Xu}$, Oei, Liu, Wang, \& Ding, 2014). In studies performed on helpfulness, those partaking in volunteer works were found to be healthier and have higher levels of well-being than those who do not volunteer. Another hypothesis found in the literature also states volunteer work to strengthen and broaden one's social relations and social relations to also be a significant predictor of happiness, health, depression, and long life (Borgonovi, 2008). While one study found the sense of awe related to peace provides an indicator of people's pro-social behaviors (Piff, Dietze, Feinberg, Stancato, \& Keltner, 2015), another study supported the intercultural findings that pro-social behaviors increase well-being (Aknin et al., 2013). Individuals that show self-esteem and helpful behaviors are seen to have high levels of life satisfaction and desire to live and to experience low levels of depression, anxiety and somatization (Post, 2005). The characteristic of helpfulness is seen as a significant predictor of psychological wellbeing (Kahana, Bhatta, Lovegreen, Kahana, \& Midlarsky, 2013).

Acceptance. According to social comparison theories, how one positions oneself around others can affect their happiness (Diener et al, 1999). Having convictions closely relates to being thankful, patient, and accepting. Being thankful is said to positively contribute to peoples' happiness and psychological/physical well-being. In addition, being thankful is positively related to pro-social characteristics like helpfulness, forgiveness, and empathy and with the personal characteristic of docility (Emmons \& McCullough, 2004; McCullough, Emmons, \& Tsang, 2002). The 
positive effects of being thankful on psychological and social health have been proven through experimental studies (Emmons \& McCullough, 2003). Materialist people have lower levels of autonomy, competence and relevance, thankfulness, meaning in life and purpose (Kashdan \& Breen, 2007). Spending less and consuming less in time surprisingly makes one happier (Chancellor \& Lyubomirsky, 2014). While life satisfaction relates to the extent that life expectations are met (Diener, Emmons, Larsen, \& Griffin, 1985), the concept of conviction expresses being satisfied with opportunities by accepting what one has achieved even if not a life in harmony with one's ideals . From this point, having convictions overlaps with the acceptance and being in harmony that is found in the judgments of Eastern societies.

Spirituality. According to a study investigating the relationship between religiosity and altruism using the phenomenological research method, while religiosity increases altruism, altruism also increases happiness. Meanwhile, religiosity increases happiness, and happy people are more willing to also help others (Pessi, 2011). The relationships between religious belief and well-being are generally found to be positive (Cohen, 2002; Tiliouine, Cummins, \& Davern, 2009; Zullig, Ward, \& Horn, 2006). Personal well-being, one of the concepts that express the eudemonic approach, shows a positive relationship with spirituality (Wills, 2009). While investigating the relationships of spirituality and religiosity with happiness, the sample group's qualities of religiosity displayed importance. This relationship can be said to tend to be low in regions where religious institutions' social functions are less important and believers are in the minority. Therefore religiosity's relationship with how much it increases happiness is not important; investigating the relationship of religiosity and happiness in people with which characteristics under which conditions is important (Snoep, 2008). While positive religious achievement is positively related with life satisfaction, negative religious achievement has a negative relationship with life satisfaction (Pargament, Feuille, \& Burdzy, 2011).

The developmental strength of problems. Researchers have stated that individuals, after a difficult life event, can revert to functioning as they had previous to the event, can become more resilient, and positive changes can be realized even in the result of struggling through difficult life crises (Lomas \& Ivtzan, 2015; O'Leary \& Ickovics, 1994; Tedeschi \& Calhoun, 1996, 2004). Some of the positive results are an increase in personal functionality like being more mature and creative, improvement in relational situations like establishing closer relations and being thankful in relations, life-philosophy changes like increased existential awareness and finding meaning in trauma, and priority changes and post-trauma spiritual development like giving less value to material resources and appreciating life (Calhoun \& Tedeschi, 2014; Tedeschi \& Calhoun, 1996, 2004). 
Optimism. Studies related to optimism have begun on establishing positive relationships between the psychology of optimism and physical health (Carver \& Scheier, 2014). Optimism positively affects the individual's subjective wellbeing in troublesome or challenging times (Carver et al., 2010). Optimism assists individuals in creating and applying healthy coping strategies (Nes \& Segerstrom, 2006). In some situations, optimism can have some negative results that are seen as a positive quality. Being pessimistic, by preparing on for the possibility of adverse outcomes, can provide one with the required motivation for preventing them (Lomas \& Ivtzan, 2015). Unrealistic optimism relates to ignoring risks and can direct harmful behaviors in terms of health like a person's smoking (Weinstein, Marcus, \& Moser, 2005). Additionally, having high expectations can lead one to become more fragile in situations where expectations are not realized.

Nature. The concept of being related to nature expresses the emotional, cognitive, and experiential relationship between man and nature (Nisbet, Zelenski, \& Murphy, 2009). The positive contributions of being associated with nature on happiness have been revealed through scientific studies (Nisbet, Zelenski, \& Murphy, 2011). Relations with nature are not just positively related with positive emotions; at the same time it positively relates with personal development of the eudemonic components of wellbeing, autonomy, and meaning of life (Nisbet \& Zelenski, 2011). Having a relationship with nature can be used for increasing well-being (Capaldi, Passmore, Nisbet, Zelenski, \& Dopko, 2015). Nature, despite its small contribution to one's experience of positive emotions, helps one to relax by reducing negative emotions (McMahan \& Estes, 2015).

Health. The energy that being healthy gives provides the ability to do the things required for living a satisfying life. Meanwhile, those with severe chronic diseases and handicaps are also seen able to live a fully-functional life. However, illness can generally be said to negatively affect well-being (Diener \& Biswas-Diener, 2011). Those in good health have been stated as feeling happier (Gerdtham \& Johannesson, 2001). Aside from the positive effects of health on well-being, research has shown health to positively affect health in well-being (Diener \& Biswas-Diener, 2011; Diener \& Chan, 2011; Howell, Kern, \& Lyubormirsky, 2007; Khaw \& Kern, 2015; Pressman \& Cohen, 2005). Experimental research has shown that as much as being healthy positvely affects well-being, well-being also positively affects health (Howell et al., 2007). Also seen important aside from one's own health is the health of those in one's surroundings.

Having a sufficient economic situation. Positive relationships between income and happiness have also been similarly shown in studies performed in the field of psychology. Because a raise in income increases opportunities and allows for improving conditions, it increases people's life satisfaction and positive affection (Diener, Tay, \& Oishi, 2013). However, the effect of economic factors on well-being 
has been expressed as limited. Income level alone is insufficient for happiness. Increases in income level advance in parallel with happiness up to a point but then stops (Easterlin, 2003). When evaluating studies done on the topic of economic situation, the correlation between happiness and money is low despite being related (Diener \& Biswas-Diener, 2002; Diener \& Lucas, 1999).

Activities. Process and activity theories emphasize the potential of engaging activities that require effort to increase well-being (Lyubomirsky \& Layous, 2013; Lyubomirsky et al., 2005b; Seligman et al., 2005). Activity theories advocate happiness to be a product of human activity (Deiner, 1984). Flow experiences that reveal activities like sports, games, art, and hobbies that come to mean fully including people in life positively affect happiness. Activities and goals that are appropriate to one's talents, skills, opportunities, and handicaps should be determined. Various activities have been stated to positively affect happiness in studies that have been done (Csikszentmihalyi, 1990; Deiner, 1984; Henricksen \& Stephens, 2013; Tkach \& Lyubomirsky, 2006).

Superficial solutions. In studies performed on the topic of dealing with stress, while problem-focused coping strategies have been included in active coping, it is more effective compared to emotion-focused coping strategies, which are defined as passive coping. However, which mechanism will be more functional is related to harmony among the strategies used with one's characteristics (Lazarus \& Folkman, 1984). The escapist-avoidance mechanism has been stated to be used generally in situations where one cannot control or change the experienced problem (Roth \& Cohen, 1986). Although these methods cannot be said to generally have a positive effect on peace and happiness, it can also help reduce negative emotions for a short time.

\section{Theory and Suggestions for Applying}

According to the research results, endeavors focusing on values and character strengths are expected to increase the levels of peace and happiness. Character strengths can be assessed in terms of self-relations through the dimensions of being self-harmonious, the self being future-oriented, and having the self be related with others. Being in harmony with the self can be attempted by strengthening the qualities of being self-conscious, feeling worthy, being self-satisfied, being able to make autonomous decisions that are in harmony with one's characteristics, and being responsible and hard-working; having a future-oriented self, by strengthening the characteristics of determining goals appropriate to the self, working to reach goals, being hopeful of the future, and being optimistic; and relating one's self to others, by drawing forth the values of tolerance, benevolence, helpfulness, fairness, and honesty. Individual and group psychological counseling applications can be 
organized by bringing forth values and character strengths to increase the levels of peace and happiness.

Social benefits of peace and happiness are found, like being self-confident, optimistic, resistant to problems, healthier, and more functional, as well as being individual, extroverted, tolerant, and maintaining good relations with people. Endeavors that positively affect peace and happiness can be performed in psychological counseling practices and training programs for individuals to maintain a more functional life.

The most significant sources of peace and happiness has been seen as relationships. Using individual and group counseling practices has been recommended based on the system of approach of interventions related to experiencing love, such as having good relations with one's family and surroundings, acquiring various pursuits, feeling socially secure and worthy; such as working for individual/social goals or for social welfare; such as experiences in harmony with social, national, and spiritual values; and such as intertwining cultural/spiritual living with nature.

\section{Limitations}

Firstly, the sources of peace and happiness arrived at in the research can enable more specific results aimed at applying more experimental studies directed at affecting the levels of the themes of peace and happiness. Because the groundedtheory research design was used in the qualitative phase and the relational/crosssectional research design has been used in the quantitative stage in this mixed methods research investigating the concepts of peace and happiness, longitudinal studies can be performed on understanding the changes over time. Secondly, because data was collected using measuring tools directed at self-narratives in the quantitative phase of the research, more objective results can be reached by using the evaluations of family/peers in addition to these measuring tools. Thirdly, because this studies sample was formed of university students and adults living in Sinop, the generalization of results is limited. Lastly, the relationship of the concepts of peace and happiness with values was investigated in the qualitative phase of this study using measuring tools developed in the research results. In future studies, more comprehensive research can be performed using multi-dimensional measuring tools like the Survey of Character Strengths (Peterson \& Seligman, 2004) related to values and the concepts of character strengths and the Portrait Values Questionnaire (Schwartz et al., 2001).

\section{Conclusion}

The findings reached in this mixed-methods research can be said to be generally supported by the literature. This study has arrived at the result that good relationships and trust, personal and social values, and character strengths are the most significant sources 
of peace and happiness. Peace, as much as and perhaps even more than happiness, has also been seen important for a good life. The results that have been reached are earnestly desired to contribute to positive psychology research and application.

\section{References}

Aknin, L. B., Barrington-Leigh, C. P., Dunn, E. W., Helliwell, J. F., Burns, J., Biswas-Diener, R., ... Norton, M. I. (2013). Prosocial spending and well-being: Cross-cultural evidence for a psychological universal. Journal of Personality and Social Psychology, 104(4), 635-652. http:// dx.doi.org/10.1037/a0031578

Andrews, F. M., \& Withey, S. B. (1976). Social indicators of well-being: Americans'perceptions of life quality. New York, NY: Plenum.

Aristotle. (trans. 2000). The Nicomachean ethics (R. Crisp, Trans.). Cambridge, UK: Cambridge University Press.

Attas, M. N. (2011). İslam'da mutluluğun anlamı ve tecrübesi [The Meaning and Experience of Happiness in Islam] (Ş. A. Düzgün, Trans.). Kelam Araştırmaları Dergisi, 9(2), 219-238.

Bacanl1, H. (2016, July). Nasıl huzurlu olunur? Benlik açısından huzur modeli [How to be Tranquil? Tranquillity Through Self-Conception]. Paper presented at the Uluslararası Manevi Rehberlik Kongresi, İstanbul, Türkiye.

Bachman, L. F. (2004). Statistical analyses for language assessment. Cambridge, UK: Cambridge University Press.

Bailey, T. C., \& Snyder, C. R. (2007). Satisfaction with life and hope: A look at age and marital status. The Psychological Record, 57(2), 233. https://doi.org/10.1007/BF03395574

Baron, R. M., \& Kenny, D. A. (1986). The moderator-mediator variable distinction in social psychological research: Conceptual, strategic and statistical considerations. Journal of Personality and Social Psychology, 51, 1173-1182. http://dx.doi.org/10.1037/0022-3514.51.6.1173

Berridge, K. C., \& Kringelbach, M. L. (2011). Building a neuroscience of pleasure and well-being. Psychological Well Being, 24, 1-3. http://dx.doi.org/10.1186/2211-1522-1-3

Blackwell, S. E., Rius-Ottenheim, N., Schulte-van Maaren, Y. W., Carlier, I. V., Middelkoop, V. D., Zitman, F. G., ... Giltay, E. J. (2013). Optimism and mental imagery: A possible cognitive marker to promote well-being?. Psychiatry Research, 206(1), 56-61. http://dx.doi.org/10.1016/j.psychres.2012.09.047

Borgonovi, F. (2008). Doing well by doing good. The relationship between formal volunteering and self-reported health and happiness. Social science \& medicine, 66(11), 2321-2334. http://dx.doi. org/ 10.1016/j.socscimed.2008.01.011

Brown, T. A. (2015). Confirmatory factor analysis for applied research. New York, NY: Guilford Press.

Buchanan, K. E., \& Bardi, A. (2010). Acts of kindness and acts of novelty affect life satisfaction. The Journal of social psychology, 150(3), 235-237. http://dx.doi.org/10.1080/00224540903365554

Butler, J., \& Kern, M. L. (2016). The PERMA-Profiler: A brief multidimensional measure of flourishing. International Journal of Wellbeing, 6(3), 1-48. http://dx.doi.org/10.5502/ijw.v6i3.526

Calhoun, L. G., \& Tedeschi, R. G. (2014). Handbook of posttraumatic growth: Research and practice. New York, NY: Routledge.

Capaldi, C. A., Passmore, H. A., Nisbet, E. K., Zelenski, J. M., \& Dopko, R. L. (2015). Flourishing in nature: A review of the benefits of connecting with nature and its application as a wellbeing intervention. International Journal of Wellbeing, 5(4), 1-16. http://dx.doi.org/10.5502/ijw.v5i4.449 
Carver, C. S., \& Scheier, M. F. (2014). Dispositional optimism. Trends in cognitive sciences, 18(6), 293-299. http://dx.doi.org/10.1016/j.tics.2014.02.003

Carver, C. S., Scheier, M. F., \& Segerstrom, S. C. (2010). Optimism. Clinical Psychology Review, 30(7), 879-889. http://dx.doi.org/10.1016/j.cpr.2010.01.006

Chamorro-Premuzic, T., Bennett, E., \& Furnham, A. (2007). The happy personality: Mediational role of trait emotional intelligence. Personality and individual differences, 42(8), 1633-1639.

Chancellor, J., \& Lyubomirsky, S. (2014). Money for happiness: The hedonic benefits of thrift. In Consumption and well-being in the material world (pp. 13-47). New York, NY: Springer Netherlands.

Cohen, A. B. (2002). The importance of spirituality in well-being for Jews and Christians. Journal of Happiness Studies, 3, 287-310. http://dx.doi.org/10.1023/A:1020656823365

Cotton Bronk, K., Hill, P. L., Lapsley, D. K., Talib, T. L., \& Finch, H. (2009). Purpose, hope, and life satisfaction in three age groups. The Journal of Positive Psychology, 4(6), 500-510. http:// dx.doi.org/10.1080/17439760903271439

Creswell, J. W. (2003). Research design: Qualitative, quantitative, and mixed methods approaches (2nd ed.). Thousands Oaks, CA: Sage.

Creswell, J. W. (2012). Educational research. Planning, conducting and evaluating quantitative and qualitative research. New Jersey, NJ: Upper Saddle River.

Creswell, J. W. (2013). Qualitative inquiry \& research design choosing among five approaches. Thousands Oaks, CA: Sage.

Creswell, J. W., \& Miller, D. L. (2000). Determining validity in qualitative inquiry. Theory into Practice, 39(3), 124-131. http://dx.doi.org/10.1207/s15430421tip39032

Creswell, J. W., \& Plano Clark V. L. (2011). Designing and conducting mixed method research. Thousand Oaks, CA: Sage.

Csikszentmihalyi, M. (1990). Flow: The psychology of optimal experience. New York, NY: Harper and Row.

Dambrun, M., Ricard, M., Després, G., Drelon, E., Gibelin, E., Gibelin, M., ... O. Michaux, (2012). Measuring happiness: From fluctuating happiness to authentic-durable happiness. Frontiers in Psychology, 3(16), 1-11. http://dx.doi.org/10.3389/fpsyg.2012.00016

Davis, L. L. (1992). Instrument review: Getting the most from a panel of experts. Applied Nursing Research, 5, 194-197. http://dx.doi.org/10.1016/S0897-1897(05)80008-4

Deci, E. L., \& Ryan, R., M. (2008). Hedonia, eudaimonia, and well-being: An introduction. Journal of Happiness Studies, 9(1), 1-11. http://dx.doi.org/10.1007/s10902-006-9018-1

Delle Fave, A., Brdar, I., Freire, T., Vella-Brodrick, D., \& Wissing, M. P. (2011a). The eudaimonic and hedonic components of happiness: Qualitative and quantitative findings. Social Indicators Research, 100(2), 185-207. http://dx.doi.org/10.1007/s11205-010-9632-5

Delle Fave, A., Brdar, I., Wissing, M. P., Araujo, U., Solano, A. C., Freire, T., ... Nakamura, J. (2016). Lay definitions of happiness across nations: The primacy of inner harmony and relational connectedness. Frontiers in psychology, 7(30), 1-23. http://dx.doi.org/10.3389/fpsyg.2016.00030

Demir, M., Orthel-Clark, H., Özdemir, M., \& Özdemir, S. B. (2015). Friendship and happiness among young adults. In Friendship and happiness (pp. 117-135). New York, NY: Springer Netherlands.

Depue, R. A., \& Morrone-Strupinsky, J. V. (2005). A neurobehavioral model of affiliative bonding: Implications for conceptualizing a human trait of affiliation. Behavioral and Brain Sciences, 28(3), 313-349. https://doi.org/10.1017/S0140525X05000063 
Diener, E. (1984). Subjective well-being. Psychological Bulletin, 95, 542-575. http://dx.doi. org/10.1037/0033-2909.95.3.542

Diener, E., \& Biswas-Diener, R. (2002). Will money increase subjective well-being? A literature review and guide to needed research. Social Indicators Research, 57, 119-169. http://dx.doi. org/10.1007/978-90-481-2350-6_6

Diener, E., \& Biswas-Diener, R. (2008). The science of optimal happiness. Boston, MA: Blackwell Publishing.

Diener, E., \& Biswas-Diener, R. (2011). Health and Happiness. In Happiness: Unlocking the mysteries of psychological wealth (pp. 27-46). Hoboken, NJ: John Wiley \& Sons.

Diener, E., \& Chan, M. Y. (2011). Happy people live longer: Subjective well-being contributes to health and longevity. Applied Psychology: Health and Well-Being, 3(1), 1-43. http://dx.doi. org/10.1111/j.1758-0854.2010.01045.x

Diener, E., \& Lucas, R. E. (1999). Personality and subjective well-being. In D. Kahn- eman, E., Diener \& N. Schwarz (Eds.), Well-being: The foundations of hedonic psychology (pp. 213-229). New York, NY: Russell Sage.

Diener, E., Emmons, R. A., Larsen, R. J., \& Griffin, S. (1985). The satisfaction with life scale. Journal of Personality Assessment, 49, 71-75. http://dx.doi.org/10.1207/s15327752jpa4901_13

Diener, E., Nickerson, C., Lucas, R. E., \& Sandvik, E. (2002). Dispositional affect and job outcomes.SocialIndicatorsResearch,59(3),229-259.http://dx.doi.org/10.1023/A:1019672513984

Diener, E., Suh, E. M., Lucas, R. E., \& Smith, H. L. (1999). Subjective well-being: Three decades of progress. Psychological Bulletin, 125, 276-302. http://dx.doi.org/10.1037/0033-2909.125.2.276

Diener, E., Suh, E., Smith, H., \& Shao, L. (1995). National differences in reported subjective well-being: Why do they occur? Social Indicators Research, 34, 7-32. http://dx.doi.org/10.1007/BF01078966

Diener, E., Tay, L., \& Oishi, S. (2013). Rising income and the subjective well-being of nations. Journal of Personality and Social Psychology, 104(2), 267-276. http://dx.doi.org/10.1037/a0030487

Duan, W., Ho, S. M., Tang, X., Li, T., \& Zhang, Y. (2014). Character strength-based intervention to promote satisfaction with life in the Chinese university context. Journal of Happiness Studies, 15(6), 1347-1361. http://dx.doi.org/10.1007/s10902-013-9479-y

Dunn, E. W., Aknin, L. B., \& Norton, M. I. (2008). Spending money on others promotes happiness. Science, 319(5870), 1687-1688. http://dx.doi.org/10.1126/science.1150952.

Easterlin, R. A. (2003). Explaining happiness. Proceedings of the National Academy of Sciences, 100(19), 11176-11183. https://doi.org/10.1073/pnas.1633144100

Ekman, P., Davidson, R. J., Ricard, M., \& Wallace, B. A. (2005). Buddhist and psychological perspectives on emotions and well-being. Current Directions in Psychological Science, 14, 59-63. http://dx.doi.org/10.1111/j.0963-7214.2005.00335.x

Emmons, R. A., \& McCullough, M. E. (2003). Counting blessings versus burdens: An experimental investigation of gratitude and subjective well-being in daily life. Journal of Personality and Social Psychology, 84, 377-389. http://dx.doi.org/10.1037/0022-3514.84.2.377. 377

Emmons, R. A., \& McCullough, M. E. (2004). The psychology of gratitude. Oxford: Oxford University Press. http://dx.doi.org/10.1093/acprof:oso/9780195150100.003.0001

Ford, B. Q., Dmitrieva, J. O., Heller, D., Chentsova-Dutton, Y., Grossmann, I., Tamir, M., . . Mauss, I. B. (2015). Culture shapes whether the pursuit of happiness predicts higher or lower well-being. Journal of Experimental Psychology: General, 144(6), 1053-1062. http://dx.doi.org/10.1037/xge0000108 
Frederick, S., \& Loewenstein, G. (1999). Hedonic adaptation. In D. Kahneman, E. Diener \& N. Schwarz (Eds.), Well-being: The foundations of hedonic psychology (pp. 302-329). New York, NY: Russell Sage.

Fredrickson, B. L. (2001). The role of positive emotions in positive psychology: The broadenand-build theory of positive emotions. American psychologist, 56(3), 218-226. http://dx.doi. org/10.1037/0003-066X.56.3.218

Fredrickson, B. L. (2013). Positive emotions broaden and build. Advances in Experimental Social Psychology, 47, 1-53. http://dx.doi.org/10.1016/B978-0-12-407236-7.00001-2

Fredrickson, B. L., Boulton, A. J., Firestine, A. M., Van Cappellen, P., Algoe, S. B., Brantley, M. M., ... Salzberg, S. (2017). Positive emotion correlates of meditation practice: A comparison of mindfulness meditation and loving-kindness meditation. Mindfulness, 8(6), 1623-1633. https:// doi.org/10.1007/s12671-017-0735-9

Froh, J. J., Sefick, W. J., \& Emmons, R. A. (2008). Counting blessings in early adolescents: An experimental study of gratitude and subjective well-being. Journal of School Psychology, 46, 213-233. https://doi.org/10.1016/j.jsp.2007.03.005

Fromm, E. (1947/2013). Man for himself: An inquiry into the psychology of ethics. New York, NY: Routledge.

Furnham, A., \& Cheng, H. (1997). Personality and happiness. Psychological Reports, 80(3), 761762. http://dx.doi.org/10.2466/pr0.1997.80.3.761

Galante, J., Galante, I., Bekkers, M. J., \& Gallacher, J. (2014). Effect of kindness-based meditation on health and well-being: A systematic review and meta-analysis. Journal of Consulting and Clinical Psychology, 82(6), 1101. http://dx.doi.org/10.1037/a0037249

Gander, F., Proyer, R. T., Ruch, W., \& Wyss, T. (2013). Strength-based positive interventions: Further evidence for their potential in enhancing well-being and alleviating depression. Journal of Happiness Studies, 14(4), 1241-1259. https://doi.org/10.1007/s10902-012-9380-0

George, D., \& Mallery, M. (2010). SPSS for windows step by step: A simple guide and reference, 17.0 update. Boston, MA: Pearson

Gilbert, P. (2009). Introducing compassion-focused therapy. Advances in Psychiatric Treatment, 15(3), 199-208. https://doi.org/10.1192/apt.bp.107.005264

Gilbert, P. (2014). The origins and nature of compassion focused therapy. British Journal of Clinical Psychology, 53(1), 6-41. https://doi.org/10.1111/bjc.12043

Gilbert, P., McEwan, K., Gibbons, L., Chotai, S., Duarte, J., \& Matos, M. (2012). Fears of compassion and happiness in relation to alexithymia, mindfulness, and self-criticism. Psychology and Psychotherapy: Theory, Research and Practice, 85(4), 374-390. https://doi.org/10.1111/j.2044-8341.2011.02046.x

Gilbert, P., McEwan, K., Mitra, R., Franks, L., Richter,A., \& Rockliff, H. (2008). Feeling safe and content: A specific affect regulation system? Relationship to depression, anxiety, stress, and self-criticism. The Journal of Positive Psychology, 3(3), 182-191. https://doi.org/10.1080/17439760801999461

Given, L. M. (2008). The Sage encyclopedia of qualitative research methods. London, UK: Sage Publications.

Glaser, B., \& Strauss, A. (1967). The discovery of grounded theory - strategies for qualitative research. Chicago, IL: Aldine Publishing Company.

Harzer, C. (2016). The eudaimonics of human strengths: The relations between character strengths and well-being. In Handbook of eudaimonic well-being (pp. 307-322). New York, NY: Springer International Publishing. 
Hayes, N., \& Joseph, S. (2003). Big 5 correlates of three measures of subjective wellbeing. Personality and Individual Differences, 34(4), 723-727. http://dx.doi.org/10.1016/ S0191-8869(02)00057-0

Henricksen, A., \& Stephens, C. (2013). The happiness-enhancing activities and positive practices inventory (HAPPI): Development and validation. Journal of Happiness Studies, 14(1), 81-98. http://dx.doi.org/10.1007/s10902-011-9317-z

Hills, P., \& Argyle, M. (2001a). Happiness, introversion-extraversion and happy introverts. Personality and Individual Differences, 30(4), 595-608. http://dx.doi.org/10.1016/S0191-8869(00)00058-1

Hills, P., \& Argyle, M. (2001b). Emotional stability as a major dimension of happiness. Personality and Individual Differences, 31(8), 1357-1364. http://dx.doi.org/10.1016/S0191-8869(00)00229-4

Howell, R., Kern, M. L., \& Lyubomirsky, S. (2007). Health benefits: Meta-analytically determining the impact of well-being on objective health outcomes. Health Psychology Review, 1, 83-136. http://dx.doi.org/10.1080/17437190701492486

Joshanloo, M. (2013). A comparison of Western and Islamic conceptions of happiness. Journal of Happiness Studies, 14(6), 1857-1874. http://dx.doi.org/10.1007/s10902-012-9406-7

Joshanloo, M. (2014). Eastern conceptualizations of happiness: Fundamental differences with Western views. Journal of Happiness Studies, 15(2), 475-493. http://dx.doi.org/10.1007/s10902-013-9431-1

Joshanloo, M., Rizwan, M., Khilji, I. A., Ferreira, M. C., Poon, W. C., Sundaram, S., ... Demir, M. (2016). Conceptions of happiness and life satisfaction: An exploratory study in 14 national groups. Personality and Individual Differences, 102, 145-148. http://dx.doi.org/10.1016/j.paid.2016.06.065

Kağıtçıbaşı, Ç. (2010). Benlik, aile ve insan gelişim: Kültürel psikoloji [Family, self, and human development across cultures: Theory and applications]. İstanbul, Turkey: Koç Üniversitesi Yayınları.

Kağıtçıbaşı, Ç. (2014). Dünden bugüne insan ve insanlar: Sosyal psikolojiye giriş [Human and humans: An introduction to social psychology]. İstanbul, Turkey: Evrim Yayınevi.

Kahana, E., Bhatta, T., Lovegreen, L. D., Kahana, B., \& Midlarsky, E. (2013). Altruism, helping, and volunteering pathways to well-being in late life. Journal of Aging and Health, 25(1), 159187. http://dx.doi.org/10.1177/0898264312469665

Kahneman, D., \& Riis, J. (2005). Living, and thinking about it: two perspectives on life. In F. A. Huppert, N. Baylis \& B. Keverne, The science of well-being (pp. 285-304). New York, NY: Oxford University Press. http://dx.doi.org/10.1093/acprof:oso/9780198567523.003.0011

Kashdan, T. B., \& Breen, W. E. (2007). Materialism and diminished well-being: Experiential avoidance as a mediating mechanism. Journal of Social and Clinical Psychology, 26, 521-539. http://dx.doi.org/10.1521/jscp.2007.26.5.521

Kasser, T. (2015). The science of values in the culture of consumption. In S. Joseph (Ed.), Positive psychology in practice: Promoting human flourishing in work, health, education, and everyday life (pp. 83-102). New York, NY: Wiley.

Kerr, S. L., O’Donovan, A., \& Pepping, C. A. (2015). Can gratitude and kindness interventions enhance well-being in a clinical sample?. Journal of Happiness Studies, 16(1), 17-36. http:// dx.doi.org/10.1007/s10902-013-9492-1

Keyes, C. L. M. (2002). The mental health continuum: From languishing to flourishing in life. Journal of Health and Social Behavior, 43, 207-222. https://doi.org/10.2307/3090197

Keyes, C. L. M. (2005). Mental illness and/or mental health? Investigating axioms of the complete state model of health. Journal of Consulting and Clinical Psychology, 73, 539-548. http:// dx.doi.org/10.1037/0022-006X.73.3.539 
Keyes, C. L. M., \& Annas, J. (2009). Feeling good and functioning well: Distinctive concepts in ancient philosophy and contemporary science. The Journal of Positive Psychology, 4(3), $197-$ 201. https://doi.org/10.1080/17439760902844228

Keyes, C. L. M., Shmotkin, D., \& Ryff, C. (2002). Optimizing well-being: The empirical encounter of two traditions. Journal of Personality and Social Psychology, 82, 1007-1022. http://dx.doi. org/10.1037/0022-3514.82.6.1007

Khaw, D., \& Kern, M. L. (2015). A cross-cultural comparison of the PERMA model of well-being. Undergraduate Journal of Psychology and Berkley, 8, 10-23.

Kjell, O., N., E., Daukantaite, D., Hefferon, K., \& Sikström, S. (2016). The harmony in life scale complements the satisfaction with life scale: Expanding the conceptualization of the cognitive component of subjective well-being. Social Indicators Research, 126(2), 893-919. http://dx.doi. org/10.1007/s11205-015-0903-z

Kline, R. B. (2015). Principles and Practice of Structural Equation Modeling. New York, NY: Guilford publications.

Kringelbach, M. L., \& Berridge, K. C. (2010). The neuroscience of happiness and pleasure. Social Research, 77(2), 659-678. Retrieved from https://www.ncbi.nlm.nih.gov/pmc/articles/PMC3008658/

Lakey, B. (2013). Perceived social support and happiness: The role of personality and relational processes. In S. A. David, I. Boiniwell \& S. C. Ayers (Eds.), The Oxford handbook of happiness (pp. 847-859). Oxford: Oxford Press.

Layous, K., \& Lyubomirsky, S. (2014). The how, why, what, when, and who of happiness. In J. Gruber \& J. Moscowitz (Eds.), The light and dark side of positive emotions (pp. 473-495). New York, NY: Oxford University Press. http://dx.doi.org/10.1093/acprof:oso/9780199926725.003.0025

Layous, K., Chancellor, J., Lyubomirsky, S., Wang, L., \& Doraiswamy, P. M. (2011). Delivering happiness: Translating positive psychology intervention research for treating major and minor depressive disorders. The Journal of Alternative and Complementary Medicine, 17(8), 675-683. http://dx.doi.org/10.1089/acm.2011.0139

Layous, K., Lee, H., Choi, I., \& Lyubomirsky, S. (2013). Culture matters when designing a successful happiness-increasing activity: A comparison of the United States and South Korea. Journal of Cross-Cultural Psychology, 44(8), 1294-1303. http://dx.doi.org/10.1177/0022022113487591

Layous, K., Nelson, S. K., Oberle, E., Schonert-Reichl, K. A., \& Lyubomirsky, S. (2012). Kindness counts: Prompting prosocial behavior in preadolescents boosts peer acceptance and well-being. PLOS ONE, 7(12), e51380. https://doi.org/10.1371/journal.pone.0051380

Lazarus, R. S., \& Folkman, S. (1984). Stress, appraisal, and coping. New York, NY: Sipringer Publisher. https://doi.org/10.1017/S0033291700031652

Lee, Y. C., Lin, Y. C., Huang, C. L., \& Fredrickson, B. L. (2013). The construct and measurement of peace of mind. Journal of Happiness studies, 14(2), 571-590. https://doi.org/10.1007/s10902012-9343-5

Lincoln, Y. S., \& Guba, E. G. (1985). Naturalistic inquiry. Beverly Hills, CA: Sage.

Littman-Ovadia, H., \& Lavy, S. (2012). Character strengths in Israel: Hebrew adaptation of the VIA inventory of strengths. European Journal of Psychological Assessment, 28, 41-50. http://dx.doi. org/10.1027/1015-5759/a000089

Lomas, T., \& Ivtzan, I. (2015). Second wave positive psychology: Exploring the positive-negative dialectics of wellbeing. Journal of Happiness Studies, 17(4), 1753-1768. http://dx.doi. org/10.1007/s10902-015-9668-y 
Lu, L. (2001). Understanding happiness: A look into the Chinese folk psychology. Journal of Happiness Studies, 2(4), 407-432. http://dx.doi.org/10.1023/A:1013944228205

Lu, L., Gilmour, R. (2006). Individual-oriented and socially oriented cultural conceptions of subjective well-being: Conceptual analysis and scale development. Asian Journal of Social Psychology, 9, 36-49. https://doi.org/10.1111/j.1367-2223.2006.00183.x

Lykken, D., \& Tellegen, A. (1996). Happiness is a stochastic phenomenon. Psychological Science, 7, 186-189. http://dx.doi.org/10.1111/j.1467-9280.1996.tb00355.x

Lyubomirsky, S. (2011). Hedonic adaptation to positive and negative experiences. In S. Folkman (Ed.), Oxford handbook of stress, health, and coping (pp. 200-224). New York, NY: Oxford University Press.

Lyubomirsky, S., \& Layous, K. (2013). How do simple positive activities increase wellbeing?. Current Directions in Psychological Science, 22(1), 57-62. http://dx.doi. org/10.1177/0963721412469809

Lyubomirsky, S., Dickerhoof, R., Boehm, J. K., \& Sheldon, K. M. (2011). Becoming happier takes both a will and a proper way: An experimental longitudinal intervention to boost well-being. Emotion, 11, 391-402. http://dx.doi.org/10.1037/a0022575

Lyubomirsky, S., King, L., \& Diener, E. (2005a). The benefits of frequent positive affect: Does happiness lead to success? Psychological Bulletin, 131, 803-855. https://doi.org/10.1037/0033-2909.131.6.803

Lyubomirsky, S., Sheldon, K. M., \& Schkade, D. (2005b). Pursuing happiness: The architecture of sustainable change. Review of General Psychology, 9, 111-131. http://dx.doi.org/10.1037/10892680.9.2.111

Marx, K., \& Engels, F. (1835/2010). Reflections of a young man on the choice of a profession. In Marx and Engels collected works, 1 (pp. 3-9). Great Britain: Lawrence \& Wishart.

McCrae, R. R., \& Costa, P. T. (2003) Personality in adulthood. New York, NY: Guilford Press.

McCullough, M. E., Emmons, R. A., \& Tsang, J. (2002). The grateful disposition: A conceptual and empiricaltopography. Journal of Personality and Social Psychology, 82, 112-27. http://dx.doi. org/10.1037//0022-3514.82.1.112

McMahan, E. A., \& Estes, D. (2015). The effect of contact with natural environments on positive and negative affect: A meta-analysis. The Journal of Positive Psychology, 10(6), 507-519. http://dx.doi.org/10.1080/17439760.2014.994224

Mongrain, M., Chin, J. M., \& Shapira, L. B. (2011). Practicing compassion increases happiness and selfesteem. Journal of Happiness Studies, 12(6), 963-981. http://dx.doi.org/10.1007/s10902-010-9239-1

Morris, S. (2012). The science of happiness: A cross-cultural perspective. In H. Selin \& G. Davey (Eds.), Happiness across cultures (pp. 435-450). Netherlands: Springer.

Myers, D. G. (2000). The funds, friends, and faith of happy people. American Psychologist, 55(1), 56-67. http://dx.doi.org/10.1037/0003-066X.55.1.56

Neff, K. D., \& Costigan, A. P. (2014). Self-compassion, wellbeing, and happiness. Psychologie in Österreich, 2(3), 114-119.

Neff, K. D., Kirkpatrick, K. L., \& Rude, S. S. (2007a). Self-compassion and adaptive psychological functioning. Journal of Research in Personality, 41, 139-154. http://dx.doi.org/10.1016/j. jrp.2006.03.004

Neff, K. D., Rude, S. S., \& Kirkpatrick, K. L. (2007b). An examination of self-compassion in relation to positive psychological functioning and personality traits. Journal of Research in Personality, 41(4), 908-916. https://doi.org/10.1016/j.jrp.2006.08.002 
Nelson, S. K., Fuller, J. A., Choi, I., \& Lyubomirsky, S. (2014). Beyond self-protection: Selfaffirmation benefits hedonic and eudaimonic well-being. Personality and Social Psychology Bulletin, 40(8), 998-1011. https://doi.org/10.1177/0146167214533389

Nelson, S. K., Kurtz, J., \& Lyubomirsky, S. (2015). What psychological science knows about achieving happiness. In S. J. Lynn, W. O’Donohue \& S. Lilienfeld (Eds.), Health, happiness, and well-being: Better living through psychological science (pp. 250-271). New York, NY: Sage.

Nes, L. S., \& Segerstrom, S. C. (2006). Dispositional optimism and coping: A meta-analytic review. Personality and Social Psychology Review, 10(3), 235-251. https://doi.org/10.1207/ s15327957pspr1003_3

Nes, R. B., Røysamb, E., Tambs, K., Harris, J. R., \& Reichborn-Kjennerud, T. (2006). Subjective well-being: Genetic and environmental contributions to stability and change. Psychological medicine, 36(07), 1033-1042. https://doi.org/10.1017/S0033291706007409

Nisbet, E. K., \& Zelenski, J. M. (2011). Underestimating nearby nature affective forecasting errors obscure the happy path to sustainability. Psychological science, 22(9), 1101-1106. https://doi. org/10.1177/0956797611418527

Nisbet, E. K., Zelenski, J. M., \& Murphy, S. A. (2009). The Nature Relatedness Scale. Linking individuals' connection with nature to environmental concern and behavior. Environment and Behavior, 41(5), 715-740. https://doi.org/10.1177/0013916508318748

Nisbet, E. K., Zelenski, J. M., \& Murphy, S. A. (2011). Happiness is in our nature: Exploring nature relatedness as a contributor to subjective well-being. Journal of Happiness Studies, 12(2), 303 322. https://doi.org/10.1007/s10902-010-9197-7

O’Leary, V. E., \& Ickovics, J. R. (1994). Resilience and thriving in response to challenge: An opportunity for a paradigm shift in women's health. Women's health (Hillsdale, NJ), 1(2), 121-142.

Oishi, S., Diener, E., Suh, E., \& Lucas, R. E. (1999). Value as a moderator in subjective wellbeing. Journal of personality, 67(1), 157-184. https://doi.org/10.1111/1467-6494.00051

Otake, K., Shimai, S., Tanaka-Matsumi, J., Otsui, K., \& Fredrickson, B. L. (2006). Happy people become happier through kindness: A counting kindnesses intervention. Journal of Happiness Studies, 7(3), 361-375. https://doi.org/10.1007/s10902-005-3650-Z

Pargament, K., Feuille, M., \& Burzdy, D. (2011). The Brief RCOPE: Current psychometric status of a short measure of religious coping. Religions, 2(1), 51-76. https://doi.org/10.3390/rel2010051

Park, N., Peterson, C., \& Seligman, M. E. P. (2004). Strengths of character and well-being. Journal of Social and Clinical Psychology, 23(5), 603-619. https://doi.org/10.1521/jscp.23.5.628.50749

Pessi, A. B. (2011). Religiosity and altruism: Exploring the link and its relation to happiness. Journal of Contemporary Religion, 26(1), 1-18. https://doi.org/10.1080/13537903.2011.539835

Peterson, C., \& Seligman, M. E. P. (2004). Character strengths and virtues a handbook and classification. New York, NY: Oxford University Press.

Pflug, J. (2009). Folk theories of happiness: A cross-cultural comparison of conceptions of happiness in Germany and South Africa. Social Indicators Research, 92(3), 551-563. https:// doi.org/10.1007/s11205-008-9306-8

Piff, P. K., Dietze, P., Feinberg, M., Stancato, D. M., \& Keltner, D. (2015). Awe, the small self, and prosocial behavior. Journal of personality and social psychology, 108(6), 883-899. http:// dx.doi.org/10.1037/pspi0000018

Post, S. G. (2005). Altruism, happiness, and health: It's good to be good. International Journal of Behavioral Medicine, 12(2), 66-77. http://dx.doi.org/10.1207/s15327558ijbm1202_4 
Pressman, S. D., \& Cohen, S. (2005). Does positive affect influence health? Psychological Bulletin, 131(6), 925-971. http://dx.doi.org/10.1037/0033-2909.131.6.925

Proyer, R. T., Gander, F., Wellenzohn, S., \& Ruch, W. (2015). Strengths-based positive psychology interventions: A randomized placebo-controlled online trial on long-term effects for a signature strengths-vs. a lesser strengths-intervention. Frontiers in psychology, 6, 456. http://dx.doi. org/10.5167/uzh-110538

Rokeach, M. (1973). The nature of human values. New York, NY: The Free Press.

Roth, S., \& Cohen, L. (1986). Approach, avoidance and coping with stress. American Psychologists, 41, 813-819. http://dx.doi.org/10.1080/0097840X.1984.9934968

Ryan, R. M., \& Deci, E. L. (2001). On happiness and human potentials: A review of research on hedonic and eudaimonic well-being. In S. Fiske (Eds.), Annual review of psychology (Vol. 52, pp.141-166). Palo Alto, CA: Annual Reviews, Inc.

Ryff, C. D., \& Singer, B. H. (2008). Know thyself and become what you are: A eudaimonic approach to psychological well-being. Journal of Happiness Studies, 9(1), 13-39. http://dx.doi. org/10.1007/s10902-006-9019-0

Schmutte, P. S., \& Ryff, C.D. (1997). Personality and well-being: Reexamining methods and meanings. Journal of Personality and Social Psychology, 73(3), 549-559. http://dx.doi. org/10.1037/0022-3514.73.3.549

Schwartz, S. H. (1992). Universals in the content and structure of values: Theory and empirical tests in 20 countries. In M. Zanna (Ed.), Advances in experimental social psychology (Vol. 25, pp. 1-65). New York, NY: Academic Press.

Schwartz, S. H. (2012). An Overview of the Schwartz Theory of Basic Values. Online Readings in Psychology and Culture, 2(1). https://doi.org/10.9707/2307-0919.1116

Schwartz, S. H., Melech, G., Lehmann, A., Burgess, S., Harris, M., \& Owens, V. (2001). Extending the cross-cultural validity of the theory of basic human values with a different method of measurement. Journal of Cross- Cultural Psychology, 32, 519-542. http://dx.doi. org/10.1177/0022022101032005001

Seligman, M. E. P. (2011). Flourish: A visionary new understanding of happiness and well-being. New York, NY: Free Press.

Seligman, M. E. P., Steen, T.A., Park, N., \& Peterson, C. (2005). Positive psychology progress: Empirical validation of interventions. American Psychologist, 60, 410-421. http://dx.doi. org/10.1037/0003-066X.60.5.410

Sheldon, K. M., \& Lyubomirsky, S. (2006). Achieving sustainable gains in happiness: Change your actions, not your circumstances. Journal of Happiness Studies, 7(1), 55-86. http://dx.doi. org/10.1007/s10902-005-0868-8

Shimai, S., Otake, K., Park, N., Peterson, C., \& Seligman, M. E. P. (2006). Convergence of character strengths in American and Japanese young adults. Journal of Happiness Studies, 7, 311-322. http://dx.doi.org/10.1007/s10902-005-3647-7

Smeets, E., Neff, K., Alberts, H., \& Peters, M. (2014). Meeting suffering with kindness: Effects of a brief self-compassion intervention for female college students. Journal of Clinical Psychology, 70(9), 794-807. http://dx.doi.org/10.1002/jclp.22076

Snoep, L. (2008). Religiousness and happiness in three nations: A research note. Journal of Happiness Studies, 9(2), 207-211. http://dx.doi.org/10.1007/s10902-007-9045-6 
Snyder, C. R. (2002). Hope theory: Rainbows in the mind. Psychological Inquiry, 13(4), 249-275. http://dx.doi.org/10.1207/S15327965PLI1304_01

Sobel, M. E. (1982). Asymptotic intervals for indirect effects in structural equations models. In S. Leinhart (Ed.), Sociological methodology (pp. 290-312). San Francisco, CA: Jossey-Bass.

Stassen, M. A., \& Staats, S. R. (1988). Hope and happiness: A comparison of some discrepancies. Social Indicators Research, 20(1), 45-58. http://dx.doi.org/10.1007/BF00384217

Stell, A. J., \& Farsides, T. (2016). Brief loving-kindness meditation reduces racial bias, mediated by positive other-regarding emotions. Motivation and Emotion, 40(1), 140-147. http://dx.doi. org/10.1007/s11031-015-9514-x

Strauss, A., \& Corbin, J. (1998). Basics of qualitative research: Techniques and procedures for developing grounded theory. London, UK: Sage Publications.

Suh, E. M. (2002). Culture, identity consistency, and subjective well-being. Journal of Personality and Social Psychology, 86, 1378-1391. http://dx.doi.org/10.1037/0022-3514.83.6.1378

Tedeschi, R. G., \& Calhoun, L. G. (1996). The Posttraumatic Growth Inventory: Measuring the positive legacy of trauma. Journal of traumatic stress, 9(3), 455-471. http://dx.doi.org/10.1002/ jts. 2490090305

Tedeschi, R. G., \& Calhoun, L. G. (2004). Posttraumatic growth: Conceptual foundations and empirical evidence. Psychological inquiry, 15(1), 1-18. http://dx.doi.org/10.1207/ s15327965pli1501_01

Tiliouine, H., Cummins, R. A., \& Davern, M. (2009). Islamic religiosity, subjective wellbeing, and health. Mental Health, Religion \& Culture, 12(1), 55-74. https://doi. org/10.1080/13674670802118099

Tkach, C., \& Lyubomirsky, S. (2006). How do people pursue happiness? Relating personality, happiness-increasing strategies, and well-being. Journal of Happiness Studies, 7(2), 183-225. http://dx.doi.org/10.1007/s10902-005-4754-1

Tsai, J. L. (2007). Ideal affect: Cultural causes and behavioral consequences. Perspectives on Psychological Science, 2(3), 242-259. http://dx.doi.org/10.1111/j.1745-6916.2007.00043.x

Tsai, J. L., Knutson, B., \& Fung, H. H. (2006). Cultural variation in affect valuation. Journal of Personality and Social Psychology, 90, 288-307. http://dx.doi.org/10.1037/0022-3514.90.2.288

Von Culin, K. R., Tsukayama, E., \& Duckworth, A. L. (2014). Unpacking grit: Motivational correlates of perseverance and passion for long-term goals. The Journal of Positive Psychology, 9(4), 306-312. http://dx.doi.org/10.1080/17439760.2014.89832

Walker, H. (2015). Joy within tranquility: Amazonian Urarina styles of happiness. HAU: Journal of Ethnographic Theory, 5(3), 177-196. https://doi.org/10.14318/hau5.3.010

Waterman, A. S. (1993). Two conceptions in happiness: contrasts of personal expressiveness (eudiamonia) and hedonic enjoyment. Journal of Personality and Social Psychology, 64, 678691. http://dx.doi.org/10.1037/0022-3514.64.4.678

Weinstein, N. D., Marcus, S. E., \& Moser, R. P. (2005). Smokers' unrealistic optimism about their risk. Tobacco Control, 14(1), 55-59. http://dx.doi.org/10.1136/tc.2004.008375

Wills, E. (2009). Spirituality and subjective well-being: Evidences for a new domain in the personal well-being index. Journal of Happiness Studies, 10(1), 49-69. http://dx.doi.org/10.1007/ s10902-007-9061-6 
Wolf, E. J., Harrington, K. M., Clark, S. L., \& Miller, M. W. (2013). Sample size requirements for structural equation models an evaluation of power, bias, and solution propriety. Educational and Psychological Measurement, 73(6), 913-934. http://dx.doi.org/10.1177/0013164413495237

Xu, W., Oei, T. P., Liu, X., Wang, X., \& Ding, C. (2014). The moderating and mediating roles of self-acceptance and tolerance to others in the relationship between mindfulness and subjective well-being. Journal of health psychology, 21(7), 1446-1456. http://dx.doi. org/10.1177/1359105314555170

Zeng, X., Chiu, C. P., Wang, R., Oei, T. P., \& Leung, F. Y. (2015). The effect of loving-kindness meditation on positive emotions: A meta-analytic review. Frontiers in psychology, 6, 1693. http://dx.doi.org/10.3389/fpsyg.2015.01693

Zessin, U., Dickhäuser, O., \& Garbade, S. (2015). The Relationship Between Self-Compassion and Well-Being: A Meta-Analysis. Applied Psychology: Health and Well-Being, 7(3), 340-364. http://dx.doi.org/10.1111/aphw.12051

Zullig, K. J., Ward, R. M., \& Horn, T. (2006). The association between perceived spirituality, religiosity, and life satisfaction: The mediating role of self-rated health. Social Indicators Research, 79, 255-274. http://dx.doi.org/10.1007/s11205-005-4127-5

\section{Appendix A}

\section{Qualitative Findings}

Theme 1: Peaceful and happy living. The category of peaceful and happy living has been presented as gathered in the sub-categories of "comforting emotions," "positive emotions," "not having negative emotions," and "peace and happiness' effects of on life." The category of comforting emotions, consisting of the codes of balance, serenity, trust, comfort, and calmness, has been expressed by the participants as: "In my opinion peace can be comfort. Namely, in everyday work, maybe in friends relationships, maybe in family relationships, the day when your head is calm, I think that says you are peaceful," G1/M/36 (G1 = Interviewee 1, M = Male, and $36=$ Age); "Peace means to feel oneself secure physically and spiritually," G14/M/60; "That which balances all your hurts, sorrows, insecurities, and volatilities..." G8/F/35 (G8 = Interviewee 8, F = Female, and $35=$ Age) .

The category of positive emotions, consisting of the codes of enthusiasm, feeling good, pleasure, happiness, and joy, has been expressed by the participants as follows: "The more enthusiastic I am, the more talkative I become. It is reflected in all I do," G23/F/37; “. .. if happiness, the soul and body enjoy that topic," G14/M/60; "Happiness, in fact expresses joy, pleasure, laughter, and enjoyment," $\mathrm{G} 13 / \mathrm{F} / 25$.

The category of not having negative emotions, formed from the codes of not being bored, not feeling tension, and not being angry, were expressed by the participants as: "I say I'm peaceful when I have no questions in my head or when I have no uneasiness," G20/M/24; “... when I feel no tension or sadness..." G7/F/43.

The category of peace and happiness' effects on life, formed from the codes healthy human relations, self-trust, tolerance, sharing peace, optimism, functionality, endurance, health, extroversion, and laughter were stated by the participants as: "If I am peaceful I feel a sense of self-trust," G21/M/28; "I love myself," G17/F/21; "The ability to get over problems...your success increases," G22/M/50; “... when peaceful it's an unhurtable, untouchable way of living," G13/F/25; "When I'm happy I want to go out and about and work on relating with people," G10/F/40; "If I 
can laugh comfortably I can say I'm happy," G1/M/36; "that I am tolerant, that I am peaceful when I'm at the center of attention, I think to say I can do these..." G3/F/45; "I am more accepting," G23/F/37; "I get along better with my husband. It also reflects onto my family environment and surroundings," G21/F/28; “...my communications with people are relaxed," G22/M/50; "When you are happy and peaceful you can make those around you happy," G25/F/21.

Theme 2: Sources of peace and happiness. The category of sources of peace is formed from the sub-categories of relationships, consistency, social virtues, acceptance, spirituality, working, the developmental strength of problems, trust, optimism, nature, health, having a sufficient economic situation, activities, and superficial solutions.

Relationships. The category of relationships, formed from the codes of family, children, friendship, love, fondness, feeling worthy, talking heart-to-heart, healthy human relations, social support, sharing, national and spiritual values, a communal purpose/social welfare, being alone, and the city experience, was expressed by the participants as: "I am at peace beside my family, beside people who value me," G17/F/21; "If my friends are by my side and I can share with them, this gives me peace," G5/M/40; "Love makes people happy," G4/F/45; "If you think about the country, the country's scholars, the things coming out, if it presents you to the world you become happy. When you read history, what Fatih did, what Ataturk did, it makes you happy..." G19/M/82; "When you depend on national and spiritual values and it fulfills these requirements, people become happy," G6/M/60; "For example, if we work a strong connection in social events for the sake of a goal, if we can arrive at the goal, or even if I can't, if we can struggle for the sake of that goal, this also makes me happy," G15/M/63; "From this angle, Sinop is a very appropriate hometown. Entwined with nature; nature itself. I try being with the earth and sea. It is enough being under a tree," G13/F/25; "I live in a city like Sinop. Thank God there is minimal thievery and shamelessness," G12/M/61.

Consistency. The category of consistency, composed of the codes of doing what is necessary, being oneself, and being pleased with oneself, was expressed by the participants as: "Peace depends a little more on what you need to do, more on what you feel," G10/F/40; "It's finding yourself. When I am peaceful, I'm finding myself," G1/M/36; "Peace is one being content with oneself. It's being satisfied with yourself," G4/F/45; "Harmony between what we want to experience in the future with what we've experienced in the past makes u peaceful," G21/M/28.

Social Virtues. The category of social virtues, formed from the codes of altruism, being useful, and tolerance, was stated by the participants as: "Our prophet has a very beautiful saying. Comfort says I can't sleep while one's neighbor is hungry. I am also saying that no matter how much you have, but if the other side is hungry, and this doesn't bother you, how can you also be peaceful if you aren't bothered by his suffering," G19/M/82; "Making a person happy. For example, I become happy too because I've made a person happy," G25/F/21; "Being helpful to someone makes me happy," G5/M/40; "Another way of being peaceful is having to be tolerant. It is not very likely looking for the fault in everything," G19/M/82.

Acceptance. The category of acceptance, formed from the codes of accepting, conviction, patience, thankfulness, being far from avarice, thinking about the negative situations of others, and not making comparisons about the positive situations of others, was expressed by the participants as: "If I accept, I reach a balance. When there is balance, there is peace," G13/F/25; "I think peace is being able to accept everything you experience, the good and the bad," G9/F/28; "A person needs to know how to do with less, to be thankful for more. Then may you find peace," G16/M/46; "One needs to be happy with what one has-I already knew this- but it appears better in my eyes," G5/M/40; "One needs to stay away from the avarice of the world to be able to be peaceful and happy," G6/M/60. 
Spirituality. The category of spirituality, composed of the codes of working to earn God's favor, the world last for no one, prayer, thinking everything is a test from God, worship, belief, destiny, things that are not tangible, spiritual knowledge, and resigning to fate, were expressed by the participants as: "Peace definitely means getting nearer to God. The closer we are to God, the more peaceful we are," G11/F/38; "Peace is in Islam. As much as one conforms to the conditions that are reflected in the experience of Islam through closeness to God, the more it creates inner peace in a person," G16/M/46; "Generally, adhering to religious and moral values gives peace," G21/M/28; "Praying salat, fasting, these provide peace in humans," G19/M/82.

Endeavor. The category of endeavor, formed from the codes of reaching goals, success, work satisfaction, and diligence, were expressed by the participants as: "If I can move straight ahead to my goals, to where I want to be in the future, I feel peaceful in that moment," G21/M/28; "Working also makes me more peaceful," G20/M/24; "Doing the work one loves. Not in the sense of profession in any case, though profession is important. Loving what you do is very necessary for peace," G4/F/45.

The developmental strength of problems. The category of the developmental strength of problems, formed from the codes of strengthening family ties, life orientation, removing fear, understanding what's important-seeing the facts, becoming mature, strength in facing problems, and being cautious in coming to see the temporariness of difficulties, was expressed by the participants as: "At first there were many serious problems in being accepted. Later we engaged more together," G23/F/37; "It strengthens family ties," G7/F/43; “...but I think it was the turning point in my life," G10/F/40; "Either you stay under your problems and get crushed, or the things you experience allow you to perceive life more differently, you become more robust, and evaluate what is important and what is not important" G4/F/45.

Trust. The category of trust, formed from the codes of justice and honesty, was expressed by the participants as: "More accurately, I feel trusted in every environment I feel peaceful," G17/F/21; "...If I can do my work honestly, then inner peace forms," (G16/M/46); "Being fair in my work and daily lives makes me peaceful," (G6/M/60).

Optimism. The category of optimism has been expressed by the participants as: "In fact, being a positive person makes me both peaceful and happy," G24/F/62; "By thinking positively, maybe overcoming these problems is also peace itself" $\mathrm{G} 6 / \mathrm{M} / 60$ ). However, being too optimistic can have some negative effects. Having high expectations can open the way to a person becoming more fragile. "I think I'm very optimistic. That's why I'm squeamish. Namely, because I definitely want to make a positive impact in the environment I enter, I want to be joyful and so on. But when I see a behavior I don't deserve across from this, I quickly become broken and squeamish," (G7/F/43).

Nature. The category of nature was expressed by the participants as: "If I am in nature, the sea, forests, trees, greenery, these are things closer to peace," G13/F/25; "I am entwined with nature. I see myself as a piece of nature. When I do thing I enjoy in nature, when I contribute to nature, it can be collecting trash, planting a tree in nature, or making a graft of a wild tree, turning into a fruit product..." G15/M/63; "I can be at peace maybe when I am alone, even while watching the sea," G17/F/21.

Health. Participants expressed the category of health as: "I will say happiness is health and peace. Frankly health always comes to mind in terms of happiness," G17/F/21; "Yunus Emre once had a beautiful saying, 'I to whom every morning am reborn.' If after waking up in the morning to my reading I can comfortably do my jobs at home, if I can pray the prayers in their time, and if I can read the newspaper when it comes, I feel peaceful. If not, I feel restless," G19/M/82; "Knowing the health of my family is very important," G3/F/45.

Having a sufficient economic level. The category of having a sufficient economic level has been expressed by the participants as: “...It surely relates with how to meet people's one need of 
desperation Maybe you'll say, 'My husband, does money provide peace?' I am not of the $100 \%$ conviction that having money is peaceful, but nothing happens either without it," G19/M/82; "Only the tangible that can sustain your life can satisfy your spiritual hunger if you have little income, this is also the second reason. But if you feel peace through the work you do, what you already have and earn gives you peace," (G2/M/47); "Economic income is as much as having enough for yourself as well as not having anyone in need," G23/F/37.

Activities. The category of activities, consisting of the codes of acquiring pursuits, reading, traveling, watching/playing sports, producing, and learning new things, was expressed by the participants as: "By acquiring pursuits like sports and like reading books," G21/M/28; "When I watch a nice film, it grips me and I am pleased. If I read a beautiful book I am very happy. If I visit a new place, traveling makes me happy and brings me much peace," G4/F/45; "Gardening, planting flower, knitting, and computer games," G7/F/43; "Either play bridge or a game of intelligence...I am also happy with these," G15/M/63; "Classical music makes me feel peaceful," G13/F/25; "I am happy learning new things," G21/M/28.

Superficial solutions. Participants expressed the category of superficial solutions, formed from the codes of thinking of different things, avoiding the environment, getting away from the environment, leaving it to time, and harmful habits, as: "If I'm in a place that makes me uncomfortable, I attempt to leave that place," G17/F/21; "Recently in particular I suddenly don't think of that myself anymore; I think of other things," G20/M/24; "I find other pursuits to forget the problems that cause restlessness," G6/M/60; "Leaving things to time is not anything I do too much in fact," G2/M/47; "I usually find temporary solutions. Whenever I am not peaceful I want to drink. These are temporary, of course I know this," G21/M/28.

Theme 3: Restless living. The category of restless living is formed of the sub-categories of negative feelings, the effects of restlessness on life, and the obstacles to peace. The sub-category of negative emotions, consisting of the codes anxiety, irritability, and sadness, were expressed by the participants as: "My worries begin, my fears begin, I feel uneasy," G17/F/21; "I get nervous when I'm restless. This nervousness also reflects into my daily life," G8/F/35; “...I get irritable when I am restless," G24/F/62; "I cannot get happy, I become glum, if I want, I also cannot laugh," G25/F/21.

Participants expressed the effects of restlessness on life, consisting of the codes of physical problems, introversion, unwillingness, negative thinking, sleep problems, and not enjoying, as: "I get palpitations. My head hurts if I am restless," G26/F/21; "I get bored with life, I don't speak," G2/M/47; “...I don't want to do anything, I don't want to see any work," G6/M/60; "You think more negatively," G22/M/50; "I take no pleasure from the things I do," G21/M/28.

The sub-category of obstacles to peace, formed from the codes of injustice, not fulfilling religious obligations, economic problems, relationship problems, people's negative behaviors, gossip, not being happy with work, bad events, being distant from autonomy, and health issues, was expressed by the participants as: "Manifesting justice. I see this as very important," G6/M/60; "I become restless when I don't do all my prayers," G11/F/38; "Failing to secure accounts is unsettling at the end of the month," G5/M/40; "A marriage going bad, Stopping struggling in that marriage. That is a very great restlessness," G4/F/45; "If I argue with those close to me I cannot be peaceful. After an argument where I am wrong but can’t accept being wrong, I become restless," G7/F/43; "Work becomes an obstacle to my being peaceful. Business life," G21/M/28; "Coming home and it's arrays; you listen to the news, everywhere is war, In the Middle East, never-ending wars, in Africa. 30 years we've experienced this. When one listens to this, they become restless," G15/M/63; "The most important thing inhibiting my peace. It's not any one thing, either, if looked at generally, it's the stat of my country, in the sense of the state of the world, I am not peaceful," G4/F/45; "When 
there is discomfort, peace also flees. This disease, it's an illness one has with one's self, with one's own body, it's in one's children and one's family," G19/M/82.

Theme 4: The value of peace. The category of the value of peace, formed from the codes of the best position, life's meaning, peace's worth, the challenge of recovering peace, the smiling child inside me, the sound within my heart, and the most beautiful way to have existence continue, has been expressed by the participants as: "Peace is the most beautiful position, where people want to reach while living in the world, and in the world, wanting to reach the hereafter," G16/M/46; "Peace is the meaning of life. When peace is not present, nothing is complete," G23/F/37; "It is when I'm aware of the moment, 'saving' that moment, I want to embark again when my head is jammed," G13/F/25; "It's as if that moment comes like it will never end. I never want that moment to end. I want that it may be like this every day," G2/M/47; "Peace is the best way to maintain existence..." G8/F/35.

Theme 5: Happiness. The category of happiness, formed from the codes of happiness in the hereafter, being remembered as a good person, passing from one's self(flow), happiness one experiences around them, and happiness integrated with unhappiness, was expressed by the participants as: "But the real happiness is not in this world -this world is the virtual world- I'm thinking the real world, the other side, is where we'll live our long life, the life of the hereafter, and there you need to be happy," G2/M/47; "I think to say poetic justice in my eyes provides the sincerely good person's happiness, the real good person," G4/F/45; "And after I die, this is the very important principle for me too. May God lay out mercy and have someone after me be able to say that she was a very good person," G24/F/62; "That moment that does not distinguish time and space, leaving myself and experiencing the environment," G18/F/23; "You cannot be happy sometimes looking around, at the world, at events, because there is nothing that will be very happy, but when I am at home, I try to be happy with my children my husband, or the little success I get from them at school," G10/F/40; "The moments I'm happy and unhappy are moments that complement each other. Unless we are unhappy, I think we wouldn't know the value of being happy either," G8/F/35; “...The teacher drew a line on the board, he wrote suffering on one end of the line and pleasure on the other. He said that whatever sorrow passes, whatever joy passes...Human life passes here between the two. It passes between sorrow and joy." G19/M/82.

Theme 6: Peace and happiness' similarities. Participants expressed the category of peace and happiness 'similarities as: "When I am peaceful, I am happy," G10/F/40; "Happiness brings peace. Peace also brings happiness," G3/F/45; "They are almost identical to each other the same things that make someone peaceful are the same things that can make them happy," G5/M/40; "I think the two complement each other..." G26/F/21.

Theme 7: Peace and happiness' differences. The category of peace and happiness' differences is formed from the codes of peace being a more general concept compared to happiness, peace being closer to the spiritual dimension and happiness being closer to the worldly dimension, peace coming before happiness, peace's long-term and happiness' momentary form, and happiness being exciting and peace being comforting. Peace being a more general concept compared to happiness was expressed by the participants as: "Happiness is within peace. Peace has a higher title than happiness," G11/F/38; "Peace is more like this, it's like something broad. I feel it encapsulates happiness more. Frankly, I think happiness is like a subjective thingy, more within. Peace is a broad concept," G17/F/21. Participants expressed peace's dimension being closer to spiritual and happiness' being closer to more worldly as: "Happiness is things much more related to this world. Earthly things," G11/F/38; "In peace, everything is not in the material dimension. It is a thing that also has a spiritual dimension," G12/M/61. Participants expressed peace coming before happiness as: "Peace is at the beginning of this business, I think that where there is no peace, there is no happiness," G14/M/60; "The thing that creates happiness is a person being peaceful. When I am peaceful, I become happy," G15/M/63; "Peace is a thing that comes from within. I think peace is that 
innerness that enables happiness to be caught," G8/F/35. Peace's long-term and happiness' momentary form was stated by the participants as: "But for happiness, it's like it needs to be more concrete things, more momentary things. Peace is a little more like a process. Like it lasts longer," G13/F/25; "Happiness lights up and goes out, lights up and goes out in place. There is a little more continuity in peace," G19/M/82; "Peace is to me something that feels more beautiful and refreshes people more. Happiness of course also feels beautiful, but I notice peace is long-term and happiness is shorter," G9/F/28. Peace being relaxing and happiness exciting was expressed by the participants as: "There is no excitement where there is peace. If there is peace, there is no excitement, there is balance," G13/F/25; "Peace gives a little more stillness, but happiness seriously excites people." G20/M/24.

\section{Appendix B}

\section{Findings from the Scale Development Study}

Peace Scale. The Peace Scale is found to have a one-dimensional structure consisting of 9 items that explain a total of $40.328 \%$ of the scales variance and an eigenvalue of 3.226 as a result of the descriptive factor analysis performed over the 900 total pieces of data obtained from the two samples for assessing the scale's structural validity. The scale has a Cronbach alpha of internal consistency coefficient of .78 and a test-retest reliability coefficient of .83 .

The compliance index values obtained in the results of confirmatory factor analysis applied over the Peace Scale's one-dimensional structure on the data obtained from Sample 1 are found as: $\chi^{2}$ ${ }_{(20, N=450)}=58.48, p<.001 ; C F I=.97 ; N F I=.96 ; N N F I=.96 ; S R M R=.041 ; R M S E A=.065$. The compliance index values taken from the results of confirmatory factor analysis applied over the data obtained from Sample 2 are found as: $\chi_{(20, N=450)}^{2}=74.05, p<.001 ; C F I=.96 ; N F I=.95 ; N N F I=$ .94; SRMR $=.045 ; R M S E A=.078$.

Happiness Scale. The Happiness Scale has been found to have a one-dimensional structure consisting of 6 items explaining 54.129\% of the total variance as a result of descriptive factor analysis performed over the 900 total pieces of data obtained from the two samples for evaluating the scale's structural validity. The scale has a Cronbach alpha of internal consistency coefficient of .83 and test-retest reliability coefficient of .73 .

The compliance index values taken from the results of the confirmatory factor analysis applied over evaluating the one-dimensional structure of the Happiness Scale on the data obtained from Sample 1 has been found as: $\chi_{(9, N=450)}^{2}=28.42, p<.001 ; C F I=.99 ; N F I=.98 ; N N F I=.98 ;$ SRMR $=.029 ; R M S E A=.069$. The compliance index values taken from the results of the confirmatory factor analysis applied over the data obtained from Sample 2 has been found as: $\chi^{2}{ }_{(9, N=450)}=23.83$, $p<.001 ; C F I=.99 ; N F I=.98 ; N N F I=.98 ; S R M R=.029 ; R M S E A=.061$.

Tolerance Scale. The Tolerance Scale has a one-dimensional structure formed from 6 items and an eigenvalue of 2.511 explaining $41.854 \%$ of the total variance as a result of the explanatory factor analysis performed to evaluate the scale's structural validity. The scale has a Cronbach alpha internal consistency coefficient of .72 and a test-retest reliability coefficient of .79. The compliance index values obtained as a result of confirmatory factor analysis applied over the evaluation of the Tolerance Scale's one-dimensional structure was found as: $\chi_{(9, N=450)}^{2}=12.92, p<.001 ; C F I=.99$; $N F I=.98 ; N N F I=.99 ;$ SRMR $=.025 ;$ RMSEA $=.031$.

Helpfulness Scale. The Helpfulness Scale is found to have a one-dimensional structure formed of 7 items with an eigenvalue of 2.984 explaining $42.622 \%$ of the scale's total variance as a result of the explanatory factor analysis performed for evaluating the scale's structural validity. The scale 
has a Cronbach alpha internal consistency coefficient of .76 and a test-retest reliability coefficient of .63. The compliance index values obtained in the results of confirmatory factor analysis applied over the evaluation of the scale's one-dimensional structure are found as: $\chi_{(14, N=450)}^{2}=41.74, p<$ $.001 ; C F I=.98 ; N F I=.96 ; N N F I=.96 ; S R M R=.037 ; R M S E A=.066$.

Conviction Scale. The Conviction Scale is found to have a one-dimensional structure with an eigenvalue of 3.226 explaining $53.770 \%$ of the scale's total variance as a result of the descriptive factor analysis performed for evaluating the scale's construct validity. The scale has a Cronbach alpha internal consistency coefficient of .82 and a test-retest reliability coefficient of .71 . The compliance index values obtained as a result of confirmatory factor analysis applied over evaluating the Conviction Scale's one-dimensional structure have been found as: $\chi_{(9, N=450)}^{2}=22.36, p<.01$; $C F I=.99 ; N F I=.98 ; N N F I=.98 ; S R M R=.025 ; R M S E A=.057$.

Spirituality Scale. The Spirituality Scale has a one-dimensional structure consisting of 6 items with an eigenvalue of 3.780 explaining $62.933 \%$ of the scale's variance as a result of the descriptive factor analysis performed for assessing the scale's structural validity. The scale has a Cronbach alpha internal consistency coefficient of .88 and a test-retest reliability coefficient of .60.

The compliance index values obtained as a result of the confirmatory factor analysis applied over evaluating the Spirituality Scale's one-dimensional structure have been found as: $\chi_{(9, N=450)}^{2}=34.79$, $p<.001 ; C F I=.99 ; N F I=.98 ; N N F I=.98 ; S R M R=.026 ; R M S E A=.080$. The compliance index values of the first established model have been found insufficient. Modifications were made among Items 3 and 4 after examining the modification indexes. The compliance index values obtained as a result of the confirmatory factor analysis applied over evaluating the one-dimensional structure of the Spirituality Scale after the modifications have been found as: $\chi_{(8, N=450)}^{2}=20.06, p<.05 ; C F I=$ $.99 ; N F I=.98 ; N N F I=.98 ; S R M R=.019 ; R M S E A=.058$.

Personal Values Scale. The Personal Virtues Scale has been found with a three-dimensional structure consisting of 15 items that explain $54.670 \%$ of the total variance as a result of the explanatory factor analysis performed to assess the scale's structural validity. After using the varimax rotation method, the eigenvalue for the scale's sub-dimension of responsibility was found as 2.932 and explains $19.548 \%$ of the total variance; the eigenvalue for the scale's sub-dimension of purposefulness is 2.601 and explains $17.339 \%$ of the total variance; the eigenvalue for the subscale of worthiness is 2.667 and the total variance explained is $17.783 \%$. The respective Cronbach alpha internal consistency coefficients for the sub-dimensions of responsibility, purposefulness, and worthiness have been found as $.82, .77$, and .75 and their respective test-retest reliability coefficients as $.81, .77$, and .67 . The compliance index values obtained as a result of confirmatory factor analysis applied over evaluation of the Personal Virtues Scale's three-dimensional structure have been found as : $\chi^{2}{ }_{(87, N=450)}=189.74$, $p<.001 ; C F I=.98 ; N F I=.96 ; N N F I=.98 ; S R M R=.049 ; R M S E A=.051$.

Trust in Relationships Scale. The Trust in Relationships Scale has been found to have a twodimensional structure consisting of 10 items that explain $54.209 \%$ of the scale's total variance as a result of the explanatory factor analysis performed for assessing the scale's structural validity. After using the varimax rotation method, the scale's sub-dimension of trust was found to have an eigenvalue of 2.816 and explains $29.157 \%$ of the total variance, and the scale's sub-dimension of reliability was found to have an eigenvalue of 2.605 that explains $26.052 \%$ of the scale's total variance. The Cronbach alpha internal consistency coefficients for the sub-dimensions of trust in relationships and reliability have been respectively found as .80 and .75 , and their test-retest reliability coefficients respectively as .90 and .76 . The compliance index values found as a result of confirmatory factor analysis applied over the evaluation of the Trust in Relationships Scale's two-dimensional structure are: $\chi_{(34, N=450)}^{2}=63.40, p<.001 ; C F I=.99 ; N F I=.98 ; N N F I=.99 ;$ SRMR $=.033 ; R M S E A=.044$. 